\title{
Review \\ Techniques, Tricks, and Stratagems of Oral Cavity Computed Tomography and Magnetic Resonance Imaging
}

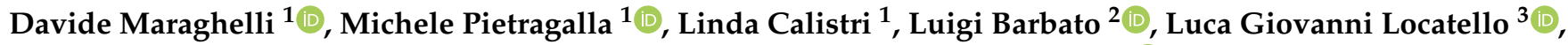 \\ Martina Orlandi ${ }^{4}$, Nicholas Landini ${ }^{5}$, Antonio Lo Casto ${ }^{6}$ and Cosimo Nardi ${ }^{1, *}$ (I)
}

1 Radiodiagnostic Unit n. 2, Department of Experimental and Clinical Biomedical Sciences, Careggi University Hospital, Largo Brambilla 3, 50134 Florence, Italy; davidemaraghelli@gmail.com (D.M.); michele.pietragalla@unifi.it (M.P.); linda.calistri@unifi.it (L.C.)

2 Research Unit in Periodontology and Periodontal Medicine, Department of Clinical and Experimental Medicine, University of Florence, 50134 Florence, Italy; luigi.barbato@unifi.it

3 Department of Otorhinolaryngology, Careggi University Hospital, Largo Brambilla, 3, 50134 Florence, Italy; locatello.lucagiovanni@gmail.com

4 Rheumatology Unit, Department of Clinical and Experimental Medicine, University of Florence, 50134 Florence, Italy; martinaorlandi@hotmail.it

5 Department of Radiology, Ca' Foncello Regional Hospital, 31100 Treviso, Italy; nikolandini@hotmail.it

6 Sezione di Scienze Radiologiche, BIND, Università degli Studi di Palermo, 90127 Palermo, Italy; antonio.locasto@unipa.it

* Correspondence: cosimo.nardi@unifi.it

check for updates

Citation: Maraghelli, D.; Pietragalla, M.; Calistri, L.; Barbato, L.; Locatello, L.G.; Orlandi, M.; Landini, N.; Lo Casto, A.; Nardi, C. Techniques, Tricks, and Stratagems of Oral Cavity Computed Tomography and

Magnetic Resonance Imaging. Appl. Sci. 2022, 12, 1473. https://doi.org/ 10.3390/app12031473

Academic Editor: Gaetano Isola

Received: 16 December 2021

Accepted: 27 January 2022

Published: 29 January 2022

Publisher's Note: MDPI stays neutral with regard to jurisdictional claims in published maps and institutional affiliations.

Copyright: (C) 2022 by the authors. Licensee MDPI, Basel, Switzerland. This article is an open access article distributed under the terms and conditions of the Creative Commons Attribution (CC BY) license (https:// creativecommons.org/licenses/by/ $4.0 /)$.

\begin{abstract}
The oral cavity constitutes a complex anatomical area that can be affected by many developmental, inflammatory, and tumoural diseases. MultiSlice Computed Tomography (MSCT) and Magnetic Resonance Imaging (MRI) currently represent the essential and complementary imaging techniques for detecting oral cavity abnormalities. Advanced MRI with diffusion-weighted imaging (DWI) and dynamic contrast-enhanced perfusion-weighted imaging (DCE-PWI) has recently increased the ability to characterise oral lesions and distinguish disease recurrences from post therapy changes. The analysis of the oral cavity area via imaging techniques is also complicated both by mutual close appositions of different mucosal surfaces and metal artifacts from dental materials. Nevertheless, an exact identification of oral lesions is made possible thanks to dynamic manoeuvres and specific stratagems applicable on MSCT and MRI acquisitions. This study summarises the currently available imaging techniques for oral diseases, with particular attention to the role of DWI, DCE-PWI, and dynamic manoeuvres. We also propose MSCT and MRI acquisition protocols for an accurate study of the oral cavity area.
\end{abstract}

Keywords: computed tomography; magnetic resonance imaging; diffusion weighted imaging; perfusion weighted imaging; oral cancer; imaging techniques

\section{Introduction}

The oral cavity constitutes a complex anatomical region divided into numerous spaces and subspaces that can be affected by many developmental, inflammatory, and tumoural pathological conditions [1-3]. The condition of greatest interest, in which diagnosis is essential to allow a correct treatment and good prognosis for patients, is certainly the tumour pathology, especially squamous cell carcinoma (SCC) that includes about $90 \%$ of all oral cavity neoplasms [3]. Oral cavity SCC is more common in eastern Europe and South Asia, with a major prevalence in male gender in the fifth decade of life. It is strongly associated with alcohol and tobacco consumption [3]. Some premalignant lesions such as leukoplakia, erythroplakia, oral lichen planus, and oral submucous fibrosis as a result of continuous exposure to risk factors can evolve into oral SCC [3]. The treatment of choice is surgical, eventually followed by adjuvant therapy: radiotherapy \pm chemotherapy depending on the TNM stage [3]. The first diagnostic step for any suspected oral pathology 
is the simple clinical examination using direct vision and white-light or enhanced-optical endoscopy that allows an easy assessment of mucosal (superficial) lesions [4,5]. MultiSlice Computed Tomography (MSCT) and Magnetic Resonance Imaging (MRI) are on the other hand crucial and complementary in the study of submucosal and infiltrating oral cavity diseases [6], whereas ultrasound and Cone Beam Computed Tomography (CBCT) still only play a marginal role $[7,8]$. Fluorine 18 -fluorodeoxyglucose positron emission tomography $\left({ }^{18} \mathrm{~F}-\mathrm{FDG}\right.$ PET $)$ does not allow a morphological evaluation such as MSCT and MRI, however, it is useful in detecting occult oral neoplasms at conventional imaging, lymph nodes and other distant metastases, and post-radiotherapy recurrences [9-11]. Dual Energy Computed Tomography (DECT) is an almost recent technique with very promising applications in the study of oral cavity cancers, although its routine use is actually limited by the poor availability both in public and private medical centres [12]. This paper is aimed to describe techniques and clinical applications of the imaging techniques used for the study of oral diseases, especially MSCT and MRI, in order to maximise the diagnostic information obtained from each examination. Regarding MSCT and MRI acquisition protocols, our experience is reported as a reference centre. Our protocols are in line with the recent guidelines drawn up by the United Kingdom-India oral cancer imaging group [13] and also with the recommendations by Drage et al. [14].

\section{Anatomy}

The oral cavity is a very complex anatomical area. It represents the most proximal portion of the foregut and continues posteriorly into the oropharynx. Its boundaries are [7]:

- Anteriorly: lips;

- Posteriorly: circumvallate papillae, tonsillar pillars, and soft palate;

- Superiorly: hard palate;

- Inferiorly: floor of the mouth and mandibular alveolar mucosal surface;

- Laterally: gingival-buccal margins on both sides;

Seven subsites are traditionally identified within the oral cavity [6].

1. Body of the tongue, the anterior two-thirds since the posterior third is a part of oropharynx;

2. Floor of the mouth, located below the lingual surface and bounded inferiorly by the mylohyoid muscle;

3. Lip, mainly formed by the orbicularis oris muscle;

4. Buccal space, a fat-containing site between the buccinator and platysma muscles;

5. Gingiva, the mucosa overlying the alveolar processes of the jaws;

6. Retromolar trigone, a triangular-shaped site formed by the mucosa posterior to the lower jaw third molar;

7. Hard palate, the bony structure that forms the palate anteriorly;

MSCT and MRI anatomy of the oral cavity including boundaries and subsites is illustrated in Figures 1 and 2. The protocols used in the acquisition of each examination are described in detail in Section 4. 


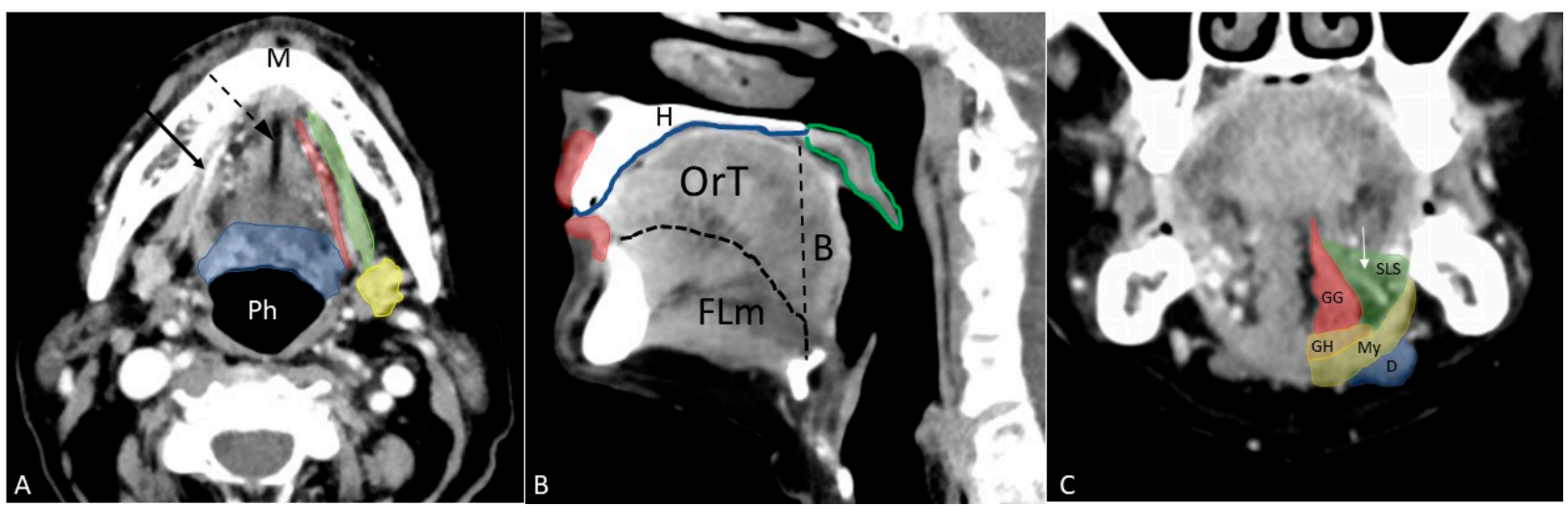

Figure 1. Anatomy of the oral cavity. (A) Axial contrast-enhanced MSCT image showing the floor of the mouth, a U-shaped space bounded inferiorly by the mylohyoid muscle (green). The floor of the mouth contains the extrinsic musculature of the tongue and the sublingual space (see Figure 1C) with the deep portion of the submandibular gland (yellow). M: mandible. Arrow: lingual artery. Dotted arrow: lingual septum. Red: hyoglossus muscle. Blue: base of the tongue which is part of the oropharynx and not of the oral cavity. Ph: pharynx. (B) Sagittal contrast-enhanced MSCT image showing the division of the tongue (OrT: oral tongue with intrinsic muscles. FLm: floor of the mouth with extrinsic muscles. B: base of the tongue). Bony hard palate $(\mathrm{H})$ and lips (red), subsites of the oral cavity. Green: soft palate and uvula, which are part of the oropharynx and not of the oral cavity. (C) Coronal contrast-enhanced MSCT image showing in detail the floor of the mouth and sublingual space. GG: genioglossus muscle. GH: geniohyoid muscle. My: mylohyoid muscle. D: anterior belly of digastric muscle. SLS: sublingual space with lingual artery inside (arrow). SLS contains anterior fibers of the $\mathrm{m}$. hyoglossus, lingual artery, vein and nerve, glossopharyngeal (IX) and hypoglossal (XII) nerves, sublingual gland and deep lobe of submandibular gland with Wharton's duct (these structures are not annotated in the image).

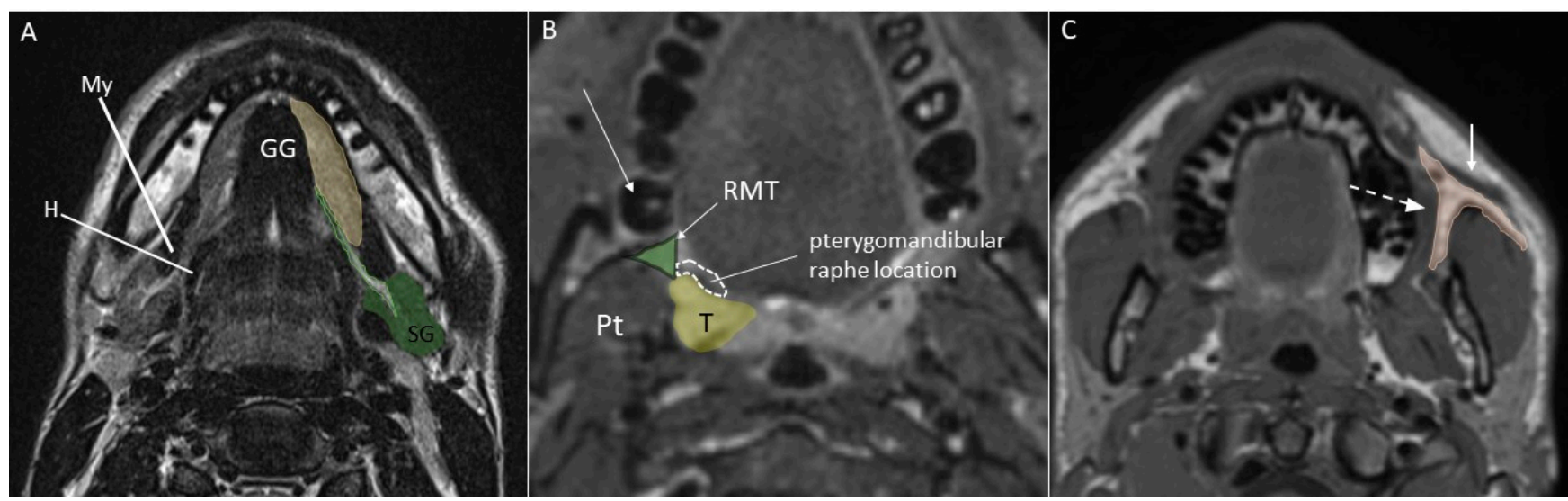

Figure 2. Anatomy of the oral cavity. (A) Axial T2 image of the floor of the mouth. Genioglossus (GG), mylohyoid (My), hyoglossus (H) muscles, with the sublingual gland (orange), deep portion of submandibular gland (SG, dark green), and Wharton's duct (light green). (B) Axial T2 fat-saturated image showing the retromolar trigone (RMT, green). It is a triangular area of mucosa between the lower jaw third molar (white arrow) and the palatine tonsil ( $\mathrm{T}$, yellow). The pterygomandibular raphe location, between the anterior tonsillar pillar and the retromolar trigone is also highlighted. Pt: medial pterygoid muscle. (C) Axial T1 image showing the buccal space (pink). It is a fat-containing subsite located between the buccinator (dotted arrow) and platysma (arrow) muscles. 


\section{Imaging Techniques}

MSCT is often the first-line investigation in the study of the oral cavity since it is widely available even in small centres. MSCT has short image acquisition times, good spatial resolution, and provides an excellent assessment of cortical bone involvement [15].

MRI comes at higher operating and technical costs per procedure than MSCT and is still as not widely available as MSCT. Notably, MRI provides the highest resolution for soft tissues, good accuracy in the detection of bone marrow involvement, and the possibility to identify a perineural tumour spread [15].

The study of the oral cavity with ultrasound can benefit from the use of two different types of probes: a transcervical high-resolution linear probe and an intra-oral probe. The former is useful for the evaluation of submandibular/submental lymph nodes in cases of oral cancer staging and as a guide for a needle biopsy. Intra-oral ultrasound with a small footprint probe can instead be used to investigate salivary ducts and glands and define the tumoural depth of invasion, that is a parameter now incorporated into the latest TNM staging system for oral cancer [7]. Nevertheless, intra-oral ultrasound has many limitations since it is both an operator-dependent technique and a new diagnostic tool with a long learning curve for radiologists [16]. Furthermore, intra-oral ultrasound cannot explore all the subsites of the oral cavity - e.g., the posterior lingual body — and images are degraded by the presence of bone surfaces that represent an obstacle to the passage of ultrasound [16].

CBCT is a technique that exploits a pyramidal $X$-ray beam striking a flat panel during a long-lasting single gantry rotation $(5-40 \mathrm{~s})$. CBCT is considered to be the most powerful tool to study bone structures because of its very high spatial resolution, but at the cost of worse temporal and contrast resolutions than MSCT $[8,17]$. CBCT is only slightly affected by very common oral metal artifacts and it has a relatively low radiation dose compared to MSCT $[17,18]$. Nevertheless, because of the long scan times with subsequent inefficacy to administer intravenous contrast agents as well as the motion artifacts, CBCT cannot replace MSCT for a large proportion of oral conditions. Therefore, in the study of the oral cavity CBCT is normally used only for the assessment of dental and bone diseases including traumatic events $[19,20]$. For this reason, a detailed analysis of CBCT was not investigated being beyond the purposes of our study.

${ }^{18} \mathrm{~F}-\mathrm{FDG}$ PET is another imaging technique with a role in the evaluation of oral neoplasms, especially SCC. It evaluates the cellular metabolism of glucose highlighting tissues with a high glucose uptake [9]. Due to its low spatial resolution, ${ }^{18}$ F-FDG PET is not useful for surgical planning since it cannot visualise the depth of invasion of the neoplasm nor the infiltration of neighbouring tissues. However, it is very useful for detecting MSCT/MRI occult primary oral tumours when their size is at least $5 \mathrm{~mm}(98 \% \mathrm{vs} .85 \%$ accuracy of ${ }^{18}$ F-FDG PET vs. MSCT /MRI) [9]. Furthermore, ${ }^{18}$ F-FDG PET is better than MSCT/MRI both to identify pathological lymph nodes and metastases and to assist in assessing post-radiotherapy recurrences $[10,11]$.

DECT is a more recent technology that uses two different $X$-ray photon energy spectra to produce images including a "conventional" spectrum and less powerful spectrum. This technique allows to procure numerous advantages. It can map or remove substances of known attenuation features, such as calcium, uric acid, and iodine. Therefore, DECT can enable both the visualisation of virtual non-contrast images when iodine is removed, eliminating the need for unenhanced imaging and the study of the iodine concentration with iodine maps [12]. The applications of DECT in the field of oral cavity oncology are represented by a better identification of tumour margins than single energy CT, a better assessment of bone involvement, and a more accurate differentiation between metastatic nodes and inflammatory/normal nodes and between recurrent disease and posttreatment changes [12].

MSCT, CBCT, ${ }^{18} \mathrm{~F}-\mathrm{FDG}$ PET, and DECT use ionising radiation, thus they present a risk of inducing neoplasms in patients. This risk can be determined by the effective dose, that estimates the probability of cancer induction. The unit of measurement of this parameter is the Sievert. Multiple examinations lead to a cumulative effective dose of radiation exposure. 
For values of cumulative effective dose $\geq 100 \mathrm{mSv}$, many organs receive a dose at which the potential stochastic effect for radiation-induced cancers is statistically significant [21]. The examination with the highest dose burden is ${ }^{18} \mathrm{~F}$-FDG PET, with a mean effective dose of $17.6 \pm 8.7 \mathrm{mSv}$ [21]. Oral cavity MSCT approximately averages $1.8 \mathrm{mSv}$ for each acquisition; considering that this examination usually consists of three acquisitions-non-enhanced, early enhanced, and late enhanced phases - the effective dose of oral cavity MSCT is around 5-6 mSv [22]. DECT provides a comparable or lower effective dose than conventional single energy CT as the aforementioned MSCT. In fact, it is important to underline how DECT allows to avoid the non-enhanced phase, replacing it with retro-reconstructed virtual non-contrast images [12]. Maxillofacial CBCT involves variable dose levels, mainly based on the different field-of-view used. However, the effective dose of CBCT is $0.25-0.7 \mathrm{mSv}$, therefore significantly lower than oral cavity MSCT [23].

Table 1 summarises the imaging techniques used for the study of oral cancer. Advantages and disadvantages of each technique are described.

Table 1. Pro and cons of the imaging techniques used for the study of oral cancer.

\begin{tabular}{|c|c|c|}
\hline Technique & Pros & Cons \\
\hline MSCT & $\begin{array}{l}\text { Widely available even in small centres, short image } \\
\text { acquisition times, high spatial resolution, excellent } \\
\text { assessment of cortical bone }\end{array}$ & $\begin{array}{c}\text { Suboptimal contrast resolution, inability to evaluate } \\
\text { bone marrow involvement and perineural tumour } \\
\text { spreading, significant dental metal artifacts, use of } \\
\text { ionising radiation }\end{array}$ \\
\hline MRI & $\begin{array}{c}\text { High resolution for soft tissues, good accuracy in the } \\
\text { detection of bone marrow involvement and } \\
\text { perineural tumour spread, no use of ionising } \\
\text { radiation }\end{array}$ & $\begin{array}{l}\text { High technical costs, not available in small centres, } \\
\text { poor evaluation of cortical bone erosion, significant } \\
\text { ferromagnetic dental metal artifacts }\end{array}$ \\
\hline Ultrasound & $\begin{array}{l}\text { Guide for needle biopsy, evaluation of the tumoural } \\
\text { depth of invasion with intra-oral probe, no use of } \\
\text { ionising radiation }\end{array}$ & $\begin{array}{l}\text { Operator-dependent technique, inability to explore } \\
\text { all the subsites of the oral cavity }\end{array}$ \\
\hline СBCT & $\begin{array}{l}\text { Optimal study of bone structures, very high spatial } \\
\text { resolution, no significant dental metal artifacts, low } \\
\text { radiation dose }\end{array}$ & $\begin{array}{l}\text { Unsatisfactory contrast resolution, low temporal } \\
\text { resolution, inability to administer intravenous } \\
\text { contrast agents, frequent motion artifacts }\end{array}$ \\
\hline${ }^{18}$ F-FDG PET & $\begin{array}{l}\text { Very good ability to detect MSCT/MRI occult } \\
\text { primary oral tumours when } \geq 5 \mathrm{~mm} \text {, lymph nodes } \\
\text { and metastases, especially in cases of } \\
\text { post-radiotherapy recurrences }\end{array}$ & $\begin{array}{l}\text { High technical costs, not available in small centres, } \\
\text { very low spatial resolution }\end{array}$ \\
\hline DECT & $\begin{array}{c}\text { Virtual non-contrast images where contrast medium } \\
\text { is not needed, more accurate in staging and } \\
\text { restaging than single energy MSCT }\end{array}$ & $\begin{array}{l}\text { Very limited availability outside the major centres, } \\
\text { use of ionising radiation }\end{array}$ \\
\hline
\end{tabular}

\section{MSCT and MRI Acquisition Protocols}

\subsection{MSCT}

The acquisition volume for the study of the oral cavity on MSCT is variable depending on clinical indications. In cases of suspected or confirmed oral cancer, the study extent is from the skull base to the upper board of the sternal manubrium in order to include infrahyoid nodes, skull base foramina that represent possible sites of perineural spread, and deep neck spaces. Intravenous administration of iodinated contrast agents is used to highlight the primary tumour, relapses, metastatic lymph nodes, and nerve enhancement [24]. On the other hand, to confirm a suspected Warthon's duct sialolithiasis, a small acquisition volume covering the oral cavity and submandibular space is enough [25].

Axial sections can be acquired at $2.5-3 \mathrm{~mm}$ thickness, but multiplanar reformations have to be generated from 0.625 or $0.75 \mathrm{~mm}$ retro-reconstructed images [24]. Generally, images are reconstructed on parallel or perpendicular planes to the hard palate in postprocessing phases, but they can be reconstructed on all possible planes as needed, even along broken or curved trajectories. Reconstructions along broken or curved trajectories 
enable representations in a two-dimensional image of volumetric anatomic structures developing on multiple planes. In cases of a suspected mandibular osteolysis, reconstructions obtained along the course of both mandibular canals allow to better define the disease extension [26]. For example, identifying the involvement of mandibular canals is decisive for staging and therapy in the case of mandibular osteoradionecrosis. Grade II osteoradionecrosis is limited to the bone above the canal-and a conservative therapy is still possible-whereas grade III osteoradionecrosis is extended to the canal and below it - and a mandibular resection is necessary [27]. At least a 16-slice multidetector CT scanner is needed to provide nearly isotropic coronal, sagittal, and oblique reformations. These multiplanar reformations that are used with bone kernel permit high-resolution views of lingual, buccal, and palatal cortical plates and alveolar ridges increasing the identification of cortical erosions (Figure 3).

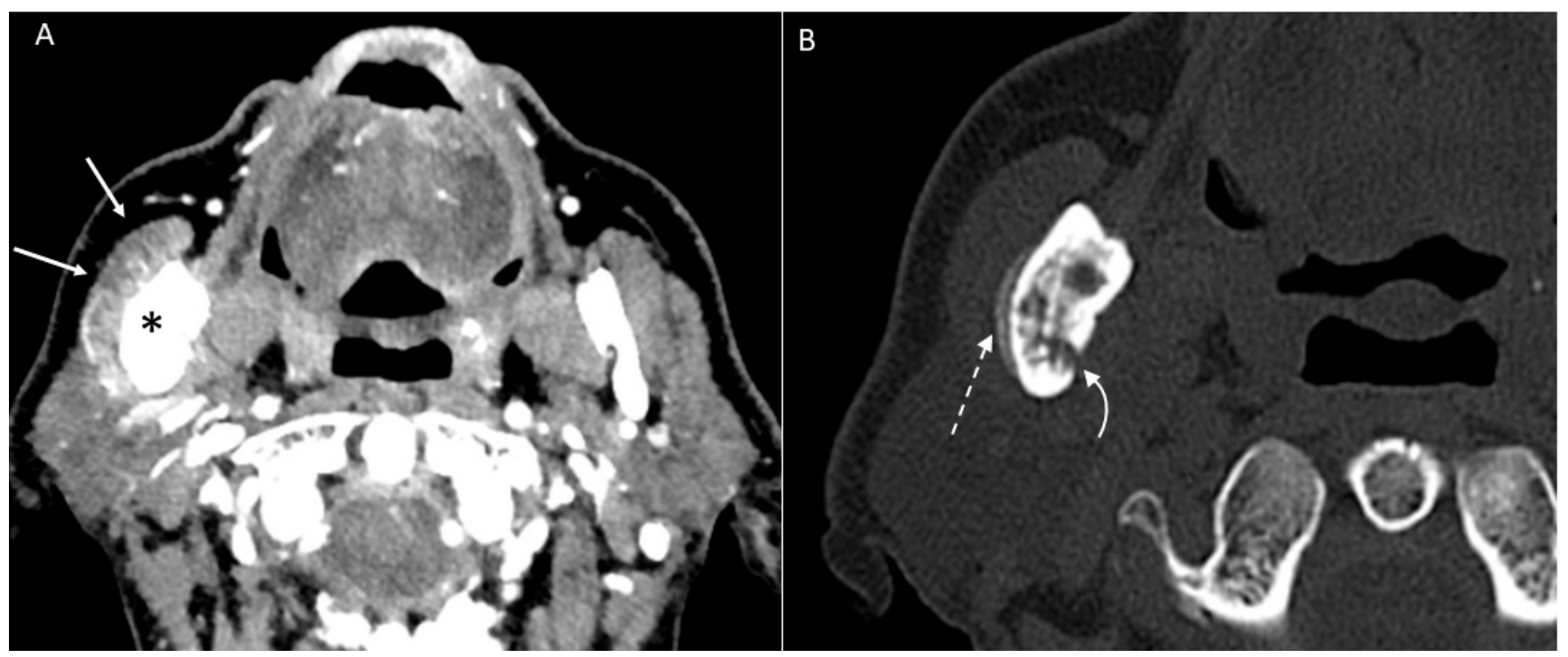

Figure 3. Soft tissue vs. bone kernel. (A) Axial contrast-enhanced soft tissue CT kernel and (B) axial bone CT kernel of the same patient with osteomyelitis of the right lower jaw with inflammation of the surrounding soft tissues. In (A) the swelling and hypervascularisation of the soft tissues (arrows) surrounding the right lower jaw $\left(^{*}\right)$ can be appreciated (see contralateral side for comparison). The bone structures are not evaluable. In (B) a periosteal reaction (dotted arrow) and focal interruption of the cortical profile can be appreciated (curved arrow).

Bone and soft tissue kernel must always be obtained in a standard MSCT scan of the oral cavity $[24,26]$. MSCT contrast phase must be performed with a scan protocol that differentiates the purely arterial phase-which highlights a fundamental landmark as the lingual artery-from the venous and interstitial phases [28]. In our centre, we are used to performing a double contrast-enhanced scan (delay 40 and $60 \mathrm{~s}$ ) at a flow rate of $3 \mathrm{~mL} / \mathrm{min}$ using $1.5 \mathrm{~mL} / \mathrm{kg}$ of intravenous iodinate contrast agent. MSCT parameters for the oral cavity standard acquisition are summarised in Table 2 . The clinical indications and acquisition protocols we provided for the study of the oral cavity via MSCT follow the guidelines drawn up by the United Kingdom-India oral cancer imaging group [13] and the recommendations by Drage et al. [14]. However, technical parameters such as collimation, pitch, rotation time, tube voltage, and tube current $\times$ exposure time need to be optimised for each specific MSCT-unit. 
Table 2. Parameters for oral cavity standard acquisitions performed with SOMATOM Definition AS 128 Slice CT Scan (Siemens Healthcare, Erlangen, Germany).

\begin{tabular}{|c|c|}
\hline Parameters & Indications \\
\hline Upper section & $\begin{array}{l}\text { Variable on the basis of clinical indications. Upper section scan should correspond to the skull base when } \\
\text { neoplasms are suspected }\end{array}$ \\
\hline Lower section & $\begin{array}{l}\text { Variable on the basis of clinical indications. Lower section scan should correspond to the upper board of } \\
\text { sternal manubrium when neoplasms are suspected }\end{array}$ \\
\hline Collimation & $0.6 \mathrm{~mm}$ \\
\hline Pitch (per tube rotation) & $0.8 \mathrm{~mm}$ \\
\hline Rotation time (per tube rotation) & $0.5 \mathrm{~s}$ \\
\hline Tube voltage * & $100 \mathrm{kV}$ (variable for optimising dose software) \\
\hline Current $\times$ exposure time ${ }^{*}$ & $170 \mathrm{mAs}$ (variable for optimising dose software) \\
\hline Window & Soft tissue: 350 HU wideness; 50 HU centre \\
\hline Type of reformation & Sagittal and coronal views \\
\hline Contrast acquisition & $\begin{array}{l}1.5 \mathrm{~mL} / \mathrm{kg} \text { of intravenous iodinate contrast material; } 3 \mathrm{~mL} / \mathrm{min} \text { flow rate; two contrast-enhanced scans } \\
\text { with delays of } 40 \text { and } 60 \mathrm{~s}\end{array}$ \\
\hline
\end{tabular}

${ }^{*}$ Mean values for an individual of $70 \mathrm{~kg}$.

\section{2. $M R I$}

Appropriate MRI examinations of suspected or confirmed oral cavity tumours should be carried out via $1.5 \mathrm{~T}$ or $3 \mathrm{~T}$ magnets with a dedicated head-neck phased array coil. Patients must undergo unenhanced and enhanced scans by intravenous gadolinium administration extending from the skull base to the upper border of the manubrium sterni. An optimised oral cavity protocol devised in our centre includes an axial T2 turbo spinecho sequence; three-dimensional fast spin-echo T1 and T2 sampling perfection with application-optimised contrasts using different flip angle evolution (SPACE) sequences with multiplanar reconstructions on axial, coronal, and sagittal planes; fat-saturated echoplanar diffusion-weighted imaging (DWI) with apparent diffusion coefficient (ADC) maps; dynamic contrast-enhanced perfusion-weighted imaging (DCE-PWI) sequences obtained through two Volumetric Interpolated Breath-hold Examination (VIBE) T1 sequences with flip angles of $5^{\circ}$ and $15^{\circ}$ for baseline T1-mapping acquisitions. After gadolinium chelates contrast agent intravenous administration (gadobutrol, Bayer, Germany; $1 \mathrm{~mL} / 10 \mathrm{~kg}$, followed by $20 \mathrm{~mL}$ saline flush at $3 \mathrm{~mL} / \mathrm{s}$ flow rate): DCE-PWI sequences obtained through one VIBE T1 sequence with a flip angle of $30^{\circ}$; an axial T1VIBE Dixon with multiplanar reconstructions on axial, coronal, and sagittal planes. Each sequence has its main use, and it is optimal for the evaluation of specific anatomic structures or phenomena [24]:

- Contrast-enhanced-T1 sequences are excellent both for the detection of enhanced masses-that sometimes are visible only after contrast administration as areas of enhancement-and perineural spread by the direct visualisation of thickened and enhanced nerves;

- Axial T2 combined with multiplanar contrast-enhanced-T1 sequences for the visualisation of tongue extrinsic muscle involvement;

- Unenhanced T1 and T2 sequences for cortical bone erosions;

- Unenhanced T1, T2 SPACE, and contrast-enhanced-T1 sequences for bone marrow involvements;

- $\quad \mathrm{T} 2$, contrast-enhanced-T1, and DWI for the assessment of lymph nodes.

Even the clinical indications and acquisition protocols used for the study of the oral cavity via MRI are in line with what is indicated by the guidelines and recommendations for oral cancer imaging studies $[13,14]$.

A more detailed analysis on the use of DWI and DCE-PWI sequences is described below. In addition, MRI parameters for oral cavity standard acquisitions are summarised in Table 3. 
Table 3. Parameters for oral cavity standard acquisitions performed with 1.5 T Magnetom Aera (Siemens Healthcare, Erlangen, Germany).

\begin{tabular}{|c|c|c|c|c|c|c|c|c|c|c|c|c|}
\hline Sequence & $\begin{array}{l}\text { Contrast } \\
\text { Agent }\end{array}$ & $\begin{array}{l}\text { Repetition } \\
\text { Time } \\
\text { (ms) }\end{array}$ & $\begin{array}{l}\text { Echo } \\
\text { Time } \\
\text { (ms) }\end{array}$ & $\begin{array}{c}\text { Slice } \\
\text { Thickness } \\
(\mathrm{mm})\end{array}$ & $\begin{array}{c}\text { Interslice } \\
\text { Gap } \\
(\mathrm{mm})\end{array}$ & $\begin{array}{c}\text { Field of } \\
\text { View }(\mathrm{mm})\end{array}$ & Matrix & $\begin{array}{l}\text { Acceleration } \\
\text { Factor }\end{array}$ & $\begin{array}{l}\text { Number of } \\
\text { Signal } \\
\text { Averaged }\end{array}$ & $\begin{array}{c}\text { Band } \\
\text { Width } \\
(\mathrm{Hz} / \mathrm{Px})\end{array}$ & $\begin{array}{l}\text { Acquisition } \\
\text { Time } \\
\text { (min:s) }\end{array}$ & $\begin{array}{l}\text { Voxel } \\
\text { Size }\end{array}$ \\
\hline $\begin{array}{l}\text { SPACE T1 } \\
\text { Sagittal }\end{array}$ & pre & 500 & 7.2 & 0.9 & - & $229 \times 229$ & $230 \times 256$ & 2 & 1.4 & 630 & $5: 47$ & $0.9 \times 0.9 \times 0.9$ \\
\hline $\begin{array}{l}\text { SPACE T2 } \\
\text { Sagittal } \\
\text { Fat-Sat }\end{array}$ & pre & 3000 & 380 & 0.9 & - & $229 \times 229$ & $230 \times 256$ & 2 & 1.4 & 698 & $5: 56$ & $0.9 \times 0.9 \times 0.9$ \\
\hline $\begin{array}{c}\text { TSE T2 } \\
\text { Axial }\end{array}$ & pre & 5050 & 117 & 3 & 0.9 & $210 \times 190$ & $261 \times 484$ & 2 & 3 & 191 & $2: 23$ & $0.5 \times 0.5 \times 3.0$ \\
\hline $\begin{array}{l}\text { SPAIR EPI-DWI } \\
\text { Axial } \\
\text { (b 50/800 s/mm²) }\end{array}$ & pre & 4100 & 55 & 3 & 0.9 & $240 \times 240$ & $102 \times 128$ & 3 & 1 & 1608 & 3:09 & $1.6 \times 1.6 \times 3.0$ \\
\hline $\begin{array}{c}\text { VIBE T1 } \\
\text { Axial (PWI-DCE) } \\
\text { Flip angle } 5-15^{\circ}\end{array}$ & pre & 10 & 2.4 & 3.5 & 0.7 & $250 \times 226$ & $139 \times 192$ & 3 & 3 & - & - & - \\
\hline $\begin{array}{c}\text { VIBE T1 } \\
\text { Axial (PWI-DCE) } \\
\text { Flip angle } 30^{\circ}\end{array}$ & post & 4.65 & 1.66 & 3.5 & 0.7 & $250 \times 226$ & $139 \times 192$ & 3 & 3 & - & $5: 50$ & $0.5 \times 0.5 \times 3.0$ \\
\hline $\begin{array}{l}\text { VIBE Dixon } \\
\text { Axial }\end{array}$ & post & 10 & 2.4 & 0.9 & 0.18 & $225 \times 225$ & $212 \times 256$ & - & 1 & 340 & $4: 37$ & $0.9 \times 0.9 \times 0.9$ \\
\hline
\end{tabular}




\subsubsection{DWI}

DWI measures the random Brownian motion of water molecules within a voxel of tissue, thus distinguishing highly cellular tissues with low diffusion coefficients (i.e., neoplasms with restricted diffusion) from scarcely cellular tissues with high diffusion coefficients (i.e., cystic or inflammatory diseases with free water diffusion). It represents an important tool in the evaluation of oral cavity lesions, especially to differentiate benign from malignant neoplasms [29]. Furthermore, it can give a contribution to characterising the different kinds of developmental, inflammatory, and tumoural alterations affecting the oral cavity. Currently, the main applications of DWI are as follows:

- Differentiate oral cavity abscesses from cystic/necrotic tumours. An abscess shows high signal on DWI trace images and low values on ADC maps $\left(0.7-0.85 \times 10^{-3} \mathrm{~mm}^{2} / \mathrm{s}\right)$ (Figure 4), whereas a cystic/necrotic tumour usually has high values on ADC maps $\left(>2.0 \times 10^{-3} \mathrm{~mm}^{2} / \mathrm{s}\right)[30-32]$;
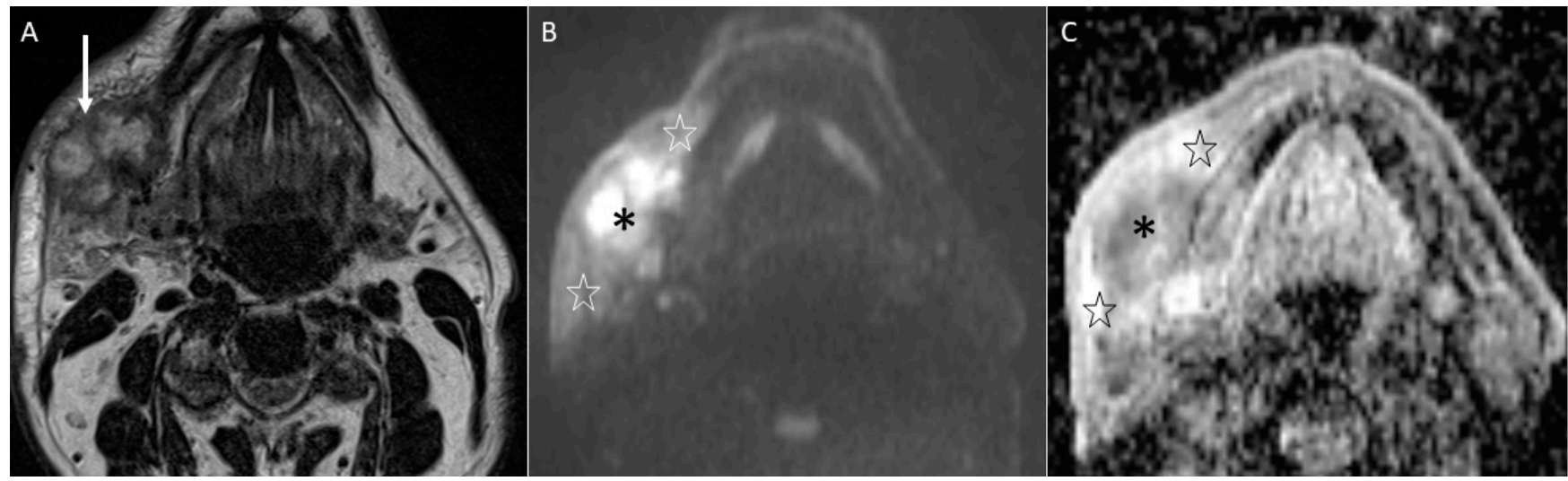

Figure 4. Odontogenic abscess with surrounding phlegmon of the right cheek soft tissues. (A) T2 axial image showing the high signal of the abscess area (white arrow). Note the swollen appearance of the soft tissues of the right cheek. (B) DWI trace $(b=1000)$. The abscess $\left(^{*}\right)$ shows high signal, whereas the surrounding phlegmon (stars in Figure 4B) has a lower signal. (C) ADC map. The purulent tissue of the abscess $\left(^{*}\right)$ has low ADC values $\left(0.84 \times 10^{-3} \mathrm{~mm}^{2} / \mathrm{s}\right.$, restricted diffusion), while the surrounding phlegmon (stars in Figure 4C) shows high ADC values without restricted diffusion $\left(2.1 \times 10^{-3} \mathrm{~mm}^{2} / \mathrm{s}\right)$.

- Differentiate colliquated from non-colliquated areas in the context of phlegmons. Inflammatory areas without abscesses have high ADC values $\left(>2.0 \times 10^{-3} \mathrm{~mm}^{2} / \mathrm{s}\right)$ [33] (Figure 4);

- Differentiate benign solid masses (ADC $1.5-1.6 \times 10^{-3} \mathrm{~mm}^{2} / \mathrm{s}$ ) from squamous cell carcinomas (ADC 1.1-1.3 $\times 10^{-3} \mathrm{~mm}^{2} / \mathrm{s}$ ) [30] (Figures 5 and 6);
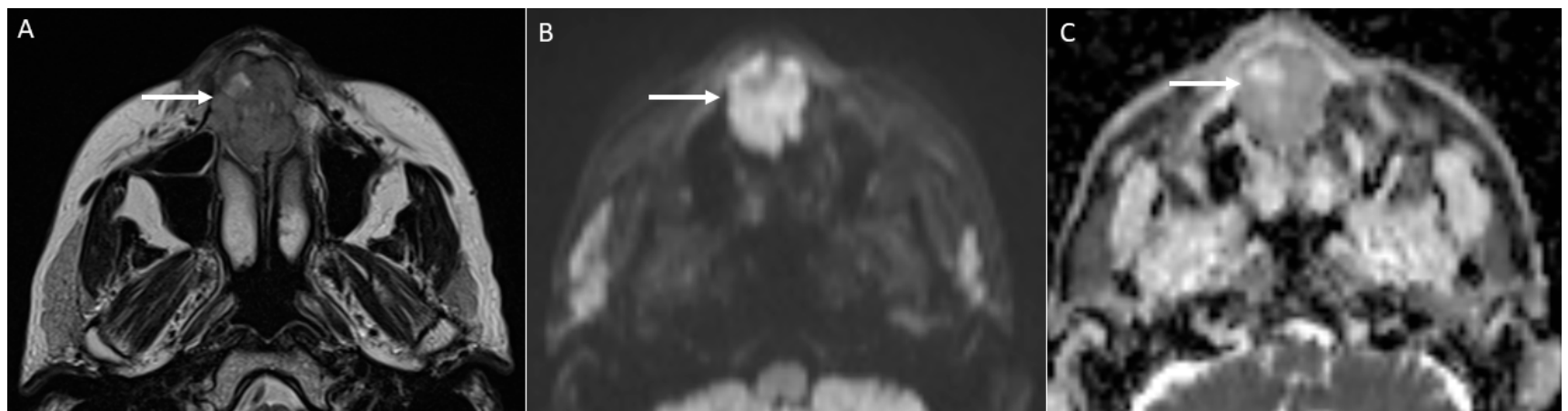

Figure 5. Squamous cell carcinoma of the hard palate. (A) Axial T2 image; (B) DWI trace (b = 1000); (C) ADC map. The mass of the hard palate (white arrows) shows restricted diffusion represented by high signal intensity on the DWI trace $(\mathbf{B})$ and low values on the ADC map $(\mathbf{C})\left(1.16 \times 10^{-3} \mathrm{~mm}^{2} / \mathrm{s}\right)$. 


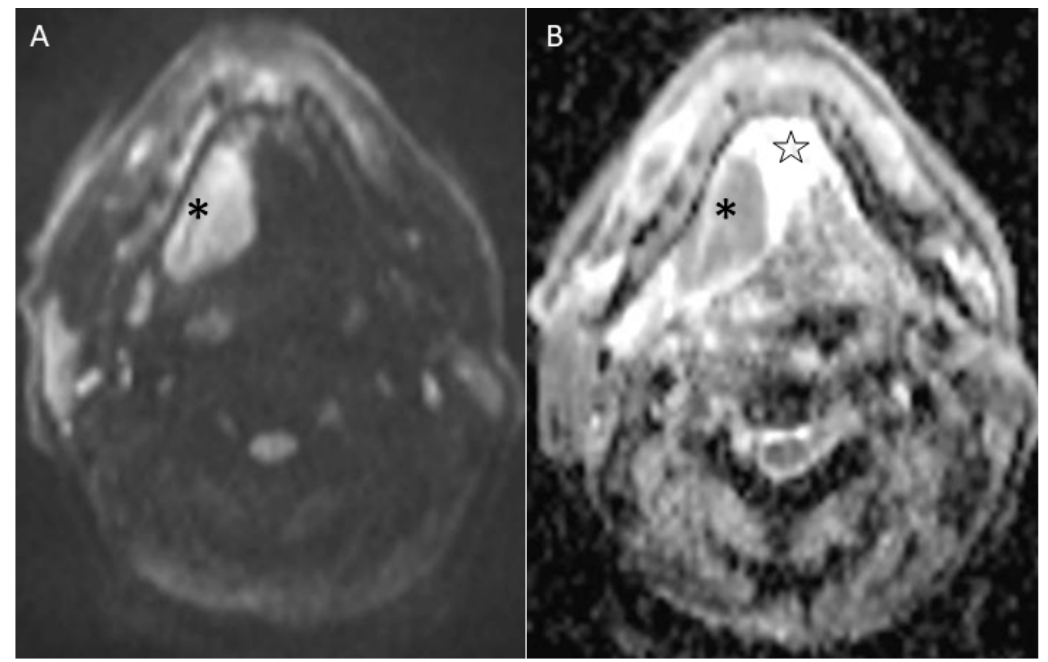

Figure 6. Squamous cell carcinoma of the mouth floor. (A) DWI trace $(b=1000)$. The neoplasm shows high signal $(*)$. (B) ADC map. Low ADC values of the neoplasm $\left(^{*}, 1.08 \times 10^{-3} \mathrm{~mm}^{2} / \mathrm{s}\right)$, whereas the surrounding inflammatory tissue shows high ADC values (star, $2.3 \times 10^{-3} \mathrm{~mm}^{2} / \mathrm{s}$ ).

- Confirm diagnostic suspicions generated by clinical workups such as oral benign cystic pathologies including ranula, periapical cyst, and nasopalatine duct cyst. Such lesions show the highest ADC values $\left(>2.0 \times 10^{-3} \mathrm{~mm}^{2} / \mathrm{s}\right)$ (Figure 7) [30];

- Characterise oral lymphoma since it shows the lowest ADC values $\left(<0.7 \times 10^{-3} \mathrm{~mm}^{2} / \mathrm{s}\right)$ because of its high cellularity (strongly crammed lymphocytes) [30]. Abscesses and lymphomas can show an overlap of ADC values around $0.7 \times 10^{-3} \mathrm{~mm}^{2} / \mathrm{s}$. However, the differential diagnosis between them is normally carried out considering both the clinical assessment and unenhanced and enhanced morphologic MRI sequences. On the contrary, poorly differentiated carcinomas can assume ADC values similar to lymphomas supported by the increase in cellularity as the grade of the tumour increases, thus making the differential diagnosis more complex [34].

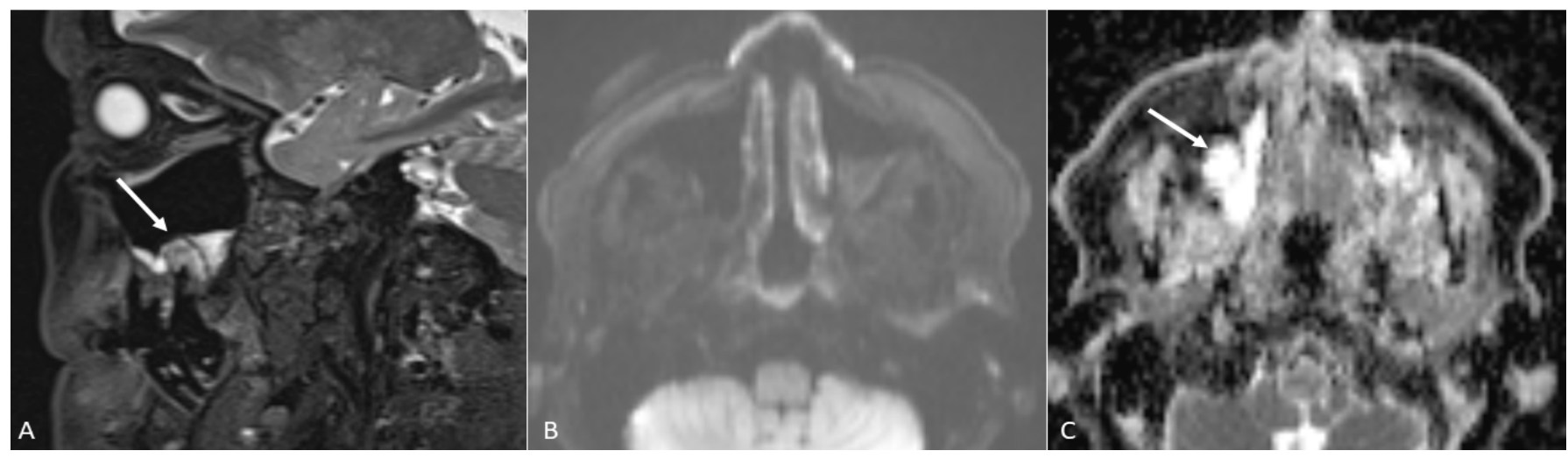

Figure 7. Periapical cysts. MRI. (A) Sagittal T2 image. (B) DWI trace b=1000. (C) ADC map. Periapical cyst (white arrows) results from dental infections that spread to the tooth apex and into the adjacent bone. It is often bordered by a thin rim of cortical bone as can be observed in (A). In (B,C) the absence of restricted diffusion is highlighted since no hyperintense signal on DWI trace and high values on ADC map $\left(2.27 \times 10^{-3} \mathrm{~mm}^{2} / \mathrm{s}\right)$ are found.

In recent years attempts have been made to use DWI to discriminate between metastatic and benign lymph nodes in patients with oral squamous cell carcinoma. This differentiation is achieved in pre-surgical phases to determine the extent of surgical neck dissections. Unfortunately, results obtained from different studies are controversial. According to Wendl et al. [35], DWI obtained with both 1.5 and 3.0 T MRI-units is not an adequate 
tool to distinguish metastatic from benign lymph nodes, whereas a more recent paper by Zhou et al. [36] found that mean ADC values of metastatic lymph nodes are significantly lower than benign lymph nodes ( 0.95 vs. $1.20 \times 10^{-3} \mathrm{~mm}^{2} / \mathrm{s}$, with a threshold of 1.035). Freihat et al. [37] achieved similar results to Zhou et al. DECT has also a role in this specific setting. Normal, inflammatory, and metastatic head-neck squamous cell carcinoma nodes show different features of microvascularity. Inflammatory nodes are those with the highest vessel density; normal nodes show a lower vascular count than inflammatory nodes but higher than metastatic ones; metastatic nodes have larger, fenestrated, and less numerous vessels. These features are reflected in a different contrast behaviour in DECT [38] Metastatic nodes have lower iodine content-i.e., a lower quantification of iodine in each voxel expressed in $\mathrm{mg} / \mathrm{mL}$ - and iodine overlay-i.e., the attenuation difference between contrast-enhanced and virtual unenhanced images expressed in Hounsfield Unit-than normal and inflammatory lymph nodes. Iodine content measurements to distinguish metastatic from normal/inflammatory nodes with a threshold value of $2.8 \mathrm{mg} / \mathrm{mL}$ show high specificity (87.5\%) and sensitivity (85.0\%) [38].

\subsubsection{DCE-PWI}

DCE-PWI consists in obtaining sequential MR images before, during, and after an intravenous bolus administration of a gadolinium agent. This technique allows the quantification of vascular biomarkers (i.e., blood volume, blood flow, and permeability) and visualisation of time/intensity curves showing the enhancement pattern of a lesion. The most studied quantitative index is Ktrans (volume transfer constant), that represents a measure of the capillary permeability. Semiquantitative time/intensity curves can be schematised in four patterns (Figure 8): progressive and slow enhancement (type A, usually typical of benign lesions), rapid achievement of the peak of enhancement followed by an equally rapid wash-out (type B, usually typical of malignant lesions), rapid achievement of the peak of enhancement followed by a plateau (type $C$, it can correspond to both benign and malignant lesions), and absence of enhancement (type D, typical of a cyst or lipoma) [39].
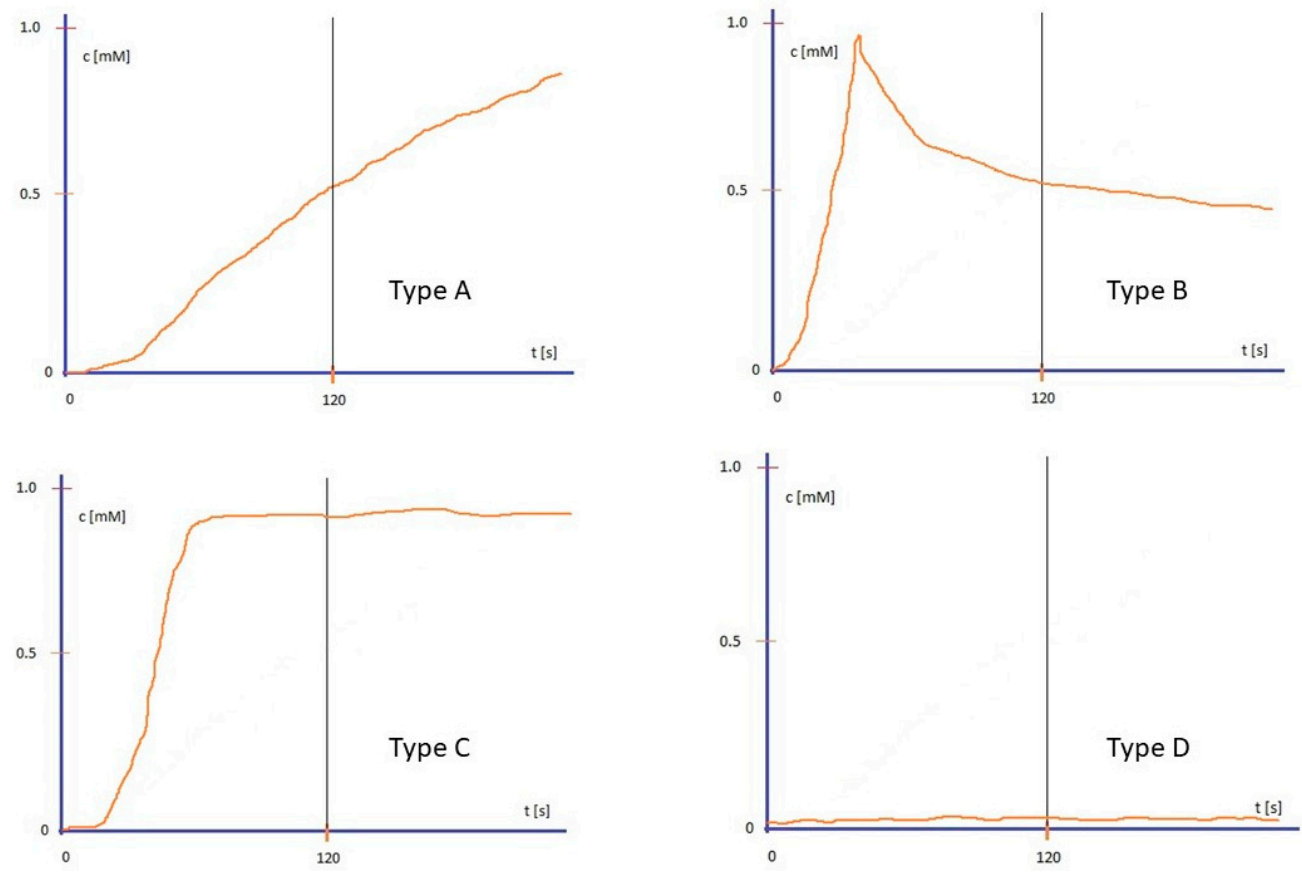

Figure 8. Time/intensity curves of dynamic contrast-enhanced perfusion weighted imaging. Explanations in the text. c: concentration of contrast agent expressed in millimoles (mM). t: time (seconds). 
As in other areas of the body, DCE-MRI is mainly used for the study of cancers in head and neck area too [40]. Different methods can be used for DCE-MRI image acquisitions, but the best one is with multiple flip angles as aforementioned. The main applications of DCE-MRI in the study of the oral cavity are represented as follows:

- Early identification of locoregional recurrences by the differentiation between local recurrences and post-treatment changes. Relapses show type B or C time/intensity curves (wash-in with wash-out or plateau), whereas post-treatment changes predominantly show type A curves (progressive enhancement). "Time factor" is crucial since a too-short interval of time from surgery or radiotherapy $(<3-4$ months) can determine false positives due to the presence of inflammatory areas and oedema with vivid enhancement [41];

- Predict pathological stages of oral cancer. For oral tongue squamous cell carcinomas, that are the most frequent malignancies of the oral cavity, staging before treatment is essential since a stage I-II TNM can be treated with a single modality therapy (preferably surgery), whereas stage III-IV TNM have to be treated with multi-modality therapy. Depending on the TNM stage, oral cavity cancers have a different microvasculature function reflected in different pharmacokinetic parameters at the quantitative DCE-MRI analysis. Stage I-II tumours show higher Ktrans values than stage III-IV tumours $\left(0.149 \pm 0.080\right.$ vs. $\left.0.106 \pm 0.057 \mathrm{~min}^{-1}\right)$ [42];

- Characterise neoplasms of the minor salivary glands, especially distinguish a pleomorphic adenoma (type A curve $\geq 85 \%$ ) from an epithelial malignancy (type $C$ curve 75-80\%) [43,44] (Figure 9);

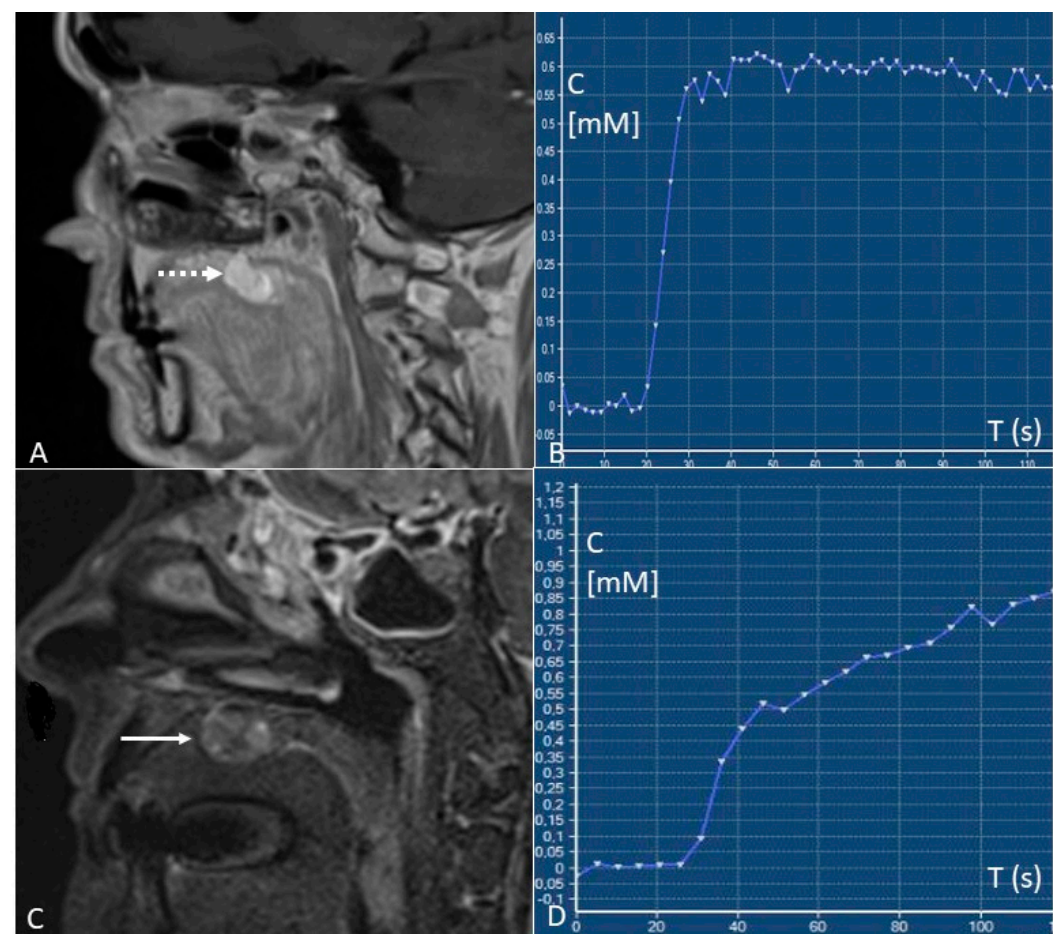

Figure 9. Malignant and benign lesions of the minor salivary glands of the palate. (A) Sagittal T1 contrast-enhanced image showing a polymorphous low-grade adenocarcinoma with vivid contrast enhancement (dotted arrow). (B) Time/intensity curve of dynamic contrast-enhanced perfusion weighted imaging. An early wash-in followed by a plateau is observed (Type C curve). C: concentration of contrast agent expressed in millimoles (mM). T: time (seconds). (C) Sagittal T2 fat-saturated image showing an unusual pleomorphic adenoma characterised by a low T2 signal intensity (arrow). (D) Time/intensity curve of dynamic contrast-enhanced perfusion weighted imaging. A progressive and slow enhancement is observed (Type A curve). C: concentration of contrast agent expressed in millimoles (mM). T: time (seconds). 
- Differentiate metastatic from normal lymph nodes. Yan et al. [45] found that the value of Ktrans in nodal metastases from squamous cell carcinoma is higher than benign nodes $\left(0.328 \pm 0.111\right.$ vs. $\left.0.141 \pm 0.065 \mathrm{~min}^{-1}\right)$;

- Predict tumour response to treatment. Although with a high metastatic potential, highly perfused tumours are considered to have a better therapeutic response because they receive a great amount of chemotherapy and are more sensitive to radiotherapy. The most accurate pre-therapy DCE-MRI parameter for predicting tumour treatment response is Ktrans. Higher pre-therapy Ktrans values are associated with a better response to therapy, with threshold values $>0.41$ to $0.84 \mathrm{~min}^{-1}$ [46].

\section{Dynamic Manoeuvres and Stratagems for the Study of the Oral Cavity via MSCT and MRI}

The mutual close apposition of different mucosal surfaces in the oral cavity represents an important obstacle in the detection of oral diseases. During MSCT and MRI acquisition phases it is possible to adopt specific stratagems for the accurate identification and assessment of localisation, size, trans-spatial extension, and deep structure invasion of oral cavity lesions. Acquisitions with dynamic manoeuvres are usually performed after intravenous administration of contrast agents and they are better tolerated by patients under MSCT than MRI due to the shorter acquisition time of MSCT examinations [28]. However, MRI can overcome some limitations of MSCT in cases of small oral cavity lesions in patients with submucosal fibrosis, retromolar trigone lesion, and post-surgical complications. Metal dental artifacts are more obvious on MSCT images too [47]. These dynamic manoeuvres can be summarised as follows:

1. Puffed cheek technique. The vestibule of the mouth is a virtual cavity due to the contact between the mucosa of the lip, cheek, and gingiva. Puffed cheek technique helps to determine if the lesion is arising from the buccal, gingival, or lingual mucosal surface since patients blow uniformly through pursed lips and the mucosal surfaces appear separated from each other. Therefore, the vestibular cavity can be appreciated as an air-filled horse-shoe-shaped space both on MSCT and MRI (Figures 10 and 11).

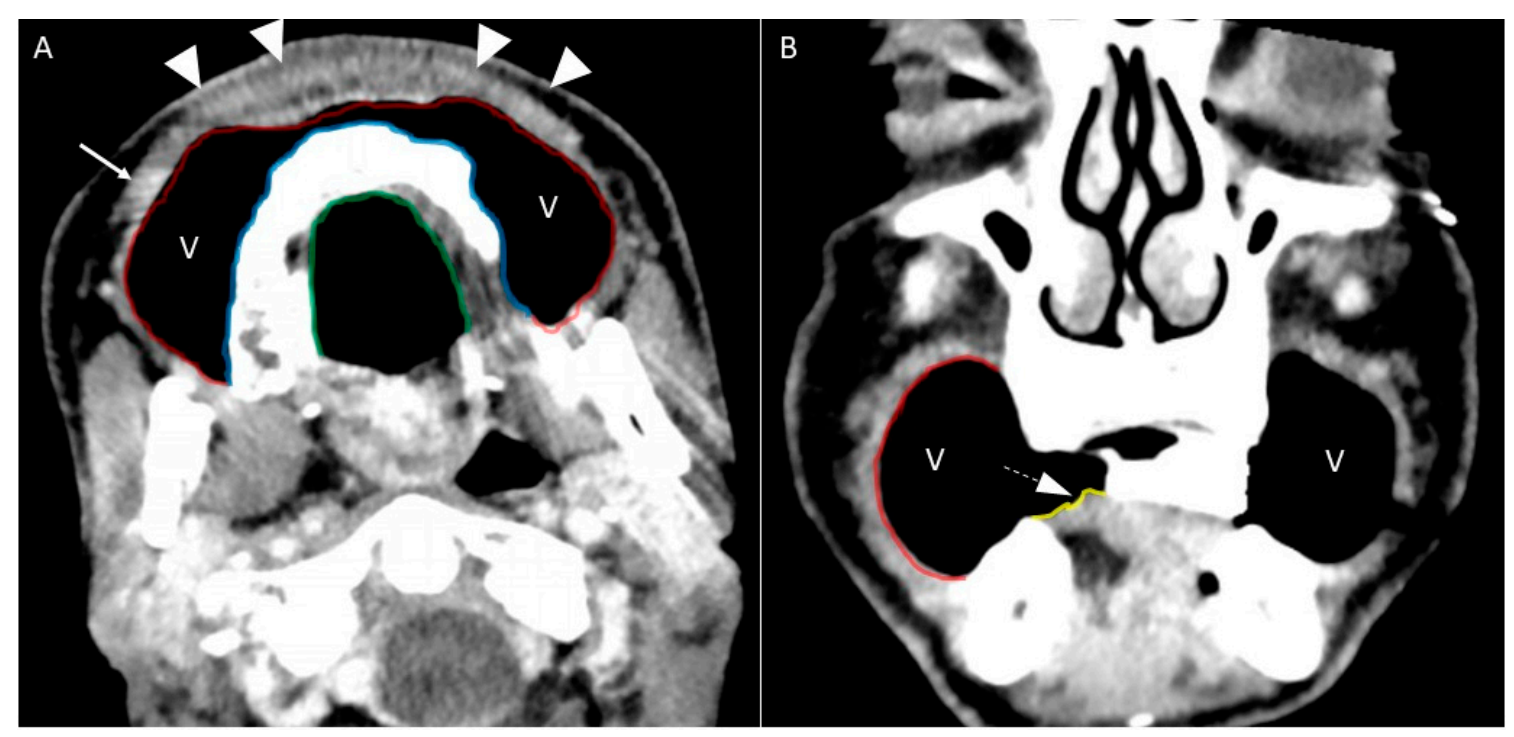

Figure 10. Puffed cheek technique. MSCT (A) Axial contrast-enhanced scan. (B) Coronal contrastenhanced scan. This technique allows to stretch and visualise the oral vestibule (V), as well as to separate the buccal (red), maxillary gingival (blue), palatal (green), and lingual (yellow, dotted arrow in (B)) mucosal surfaces. In this case, a subtle enhancing thickening in the buccal mucosa with infiltration of the buccinator muscle is highlighted (arrow in (A)). With puffed cheek technique, facial muscles (risorius, levatorangulioris, depressor angulioris, and orbicularis oris) create a broad soft tissue density pseudomass (arrowheads in (A)) that should not be confused with a real lesion. 


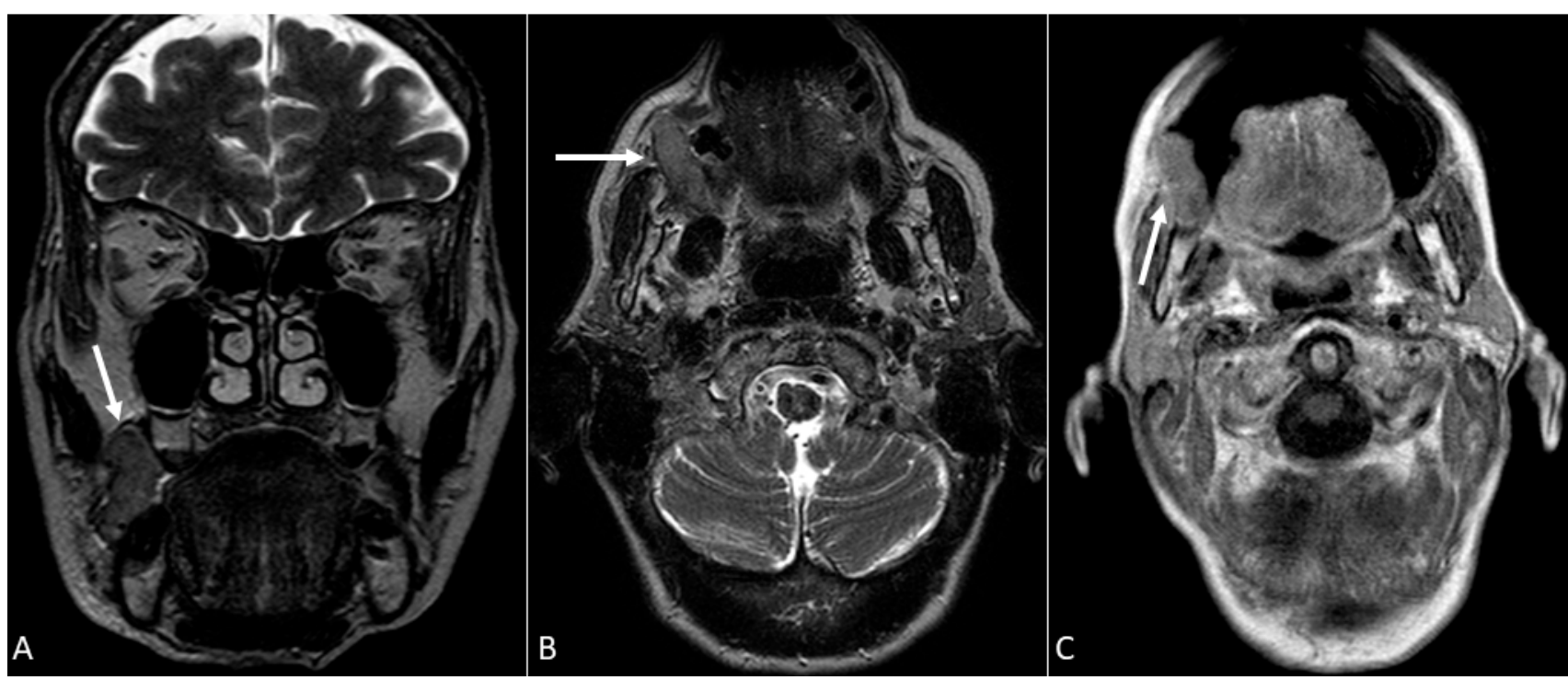

Figure 11. Puffed cheek technique. MRI. (A) Standard T2 coronal image; (B) standard T2 axial image. (C) Puffed cheek contrast-enhanced T1 axial image. Carcinoma of the right cheek mucosa (white arrows). Puffed cheek technique highlights the lesion and detached the margins of the lesion from the surrounding mucous structures well.

For best results, patients should move their tongue away from the hard palate and teeth to allow the tongue to be distinguished from the floor of the mouth/gingiva and the gingiva from the tongue/lip [47]. Henrot et al. [28] proposed a modified puffed cheek technique for MRI. The poor temporal resolution of MRI cannot enable an adequate puffed cheek technique, but the use of a cannula that insufflates the buccal vestibule allows a separation of the juxtaposed mucosal surfaces without motion and movement artifacts. The air within the oral cavity will highlight any bulky exophytic mass, subtle wall thickening, and ulceration. Buccal space and possible infiltrations of the buccinator muscle may be also better evaluated with this stratagem. Pterygomandibular raphe and retromolar trigone are also well delineated and the cheek involvement can be confirmed or precluded in cases of retromolar trigone tumours. Oral anatomy appears slightly different with the puffed cheek technique since the facial muscles create broad and band-like soft tissue density pseudomasses as the cheeks are stretched out of air and the buccinator muscles are more evident. These normal changes must not be confused with pathological masses [48]. Air within the Stensen's duct or parotid gland (pneumoparotid) is a normal finding during puffed-cheek MSCT due to the reflux of air from the mouth into Stensen's duct. This finding is not associated with infectious complications [49]. The passage of air into adjacent soft tissues through a mucosal defect-e.g., after a recent incisional biopsy—is rarely visualised and never associated with complications [50].

2. Open mouth technique. Patients open their mouth and the acquisition is obtained with quiet respiration. A device (i.e., a $50 \mathrm{~mL}$ syringe) can be used between teeth to ensure the maintenance of the right position [28]. It allows the separation of the palatal mucosa from the muscular component of the tongue clarifying the exact origin, infiltration, and thickness of tumoural masses (Figures 12 and 13). 


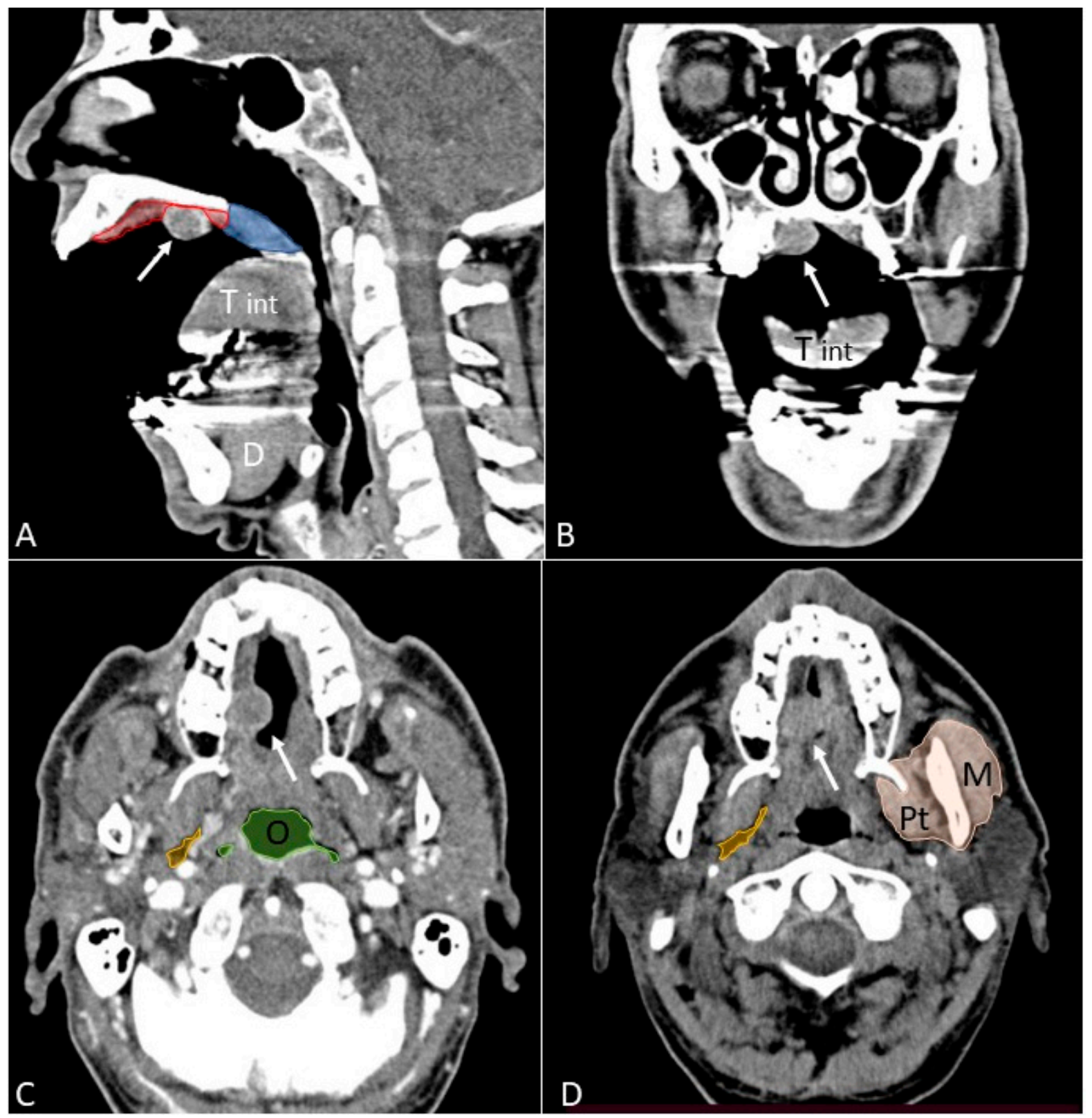

Figure 12. Open mouth MSCT technique. (A) Sagittal contrast-enhanced MSCT image showing clearly the lesion of the hard palate mucosa (arrow). The mucous lining of the hard palate (red) and soft palate (blue) are highlighted. The tongue appears different from conventional MSCT scans since with this technique the intrinsic musculature ( $\mathrm{T}$ int) is retracted, and the digastric muscle is both contracted and thickened D. The other extrinsic muscles do not appear clearly distinguishable from each other. (B) Coronal contrast-enhanced image showing the neoplasm (arrow) and the intrinsic musculature of the tongue (T int). (C) Axial contrast-enhanced image depicts the neoplasm very well (arrow). Two head and neck spaces that are not part of the oral cavity but represent pathways of tumoural diffusion and inflammatory pathologies are highlighted: the parapharyngeal fat space (yellow) and oropharyngeal mucous space with air into the pharyngeal lumen (O, green). (D) Axial conventional MSCT image shows how the neoplasm is much less visible than the open mouth technique. A further space bordering the oral cavity is highlighted: the masticator space (pink) formed at this level by the masseter $(\mathrm{M})$ and medial pterygoid $(\mathrm{Pt})$ muscles. Yellow: parapharyngeal fat space. 

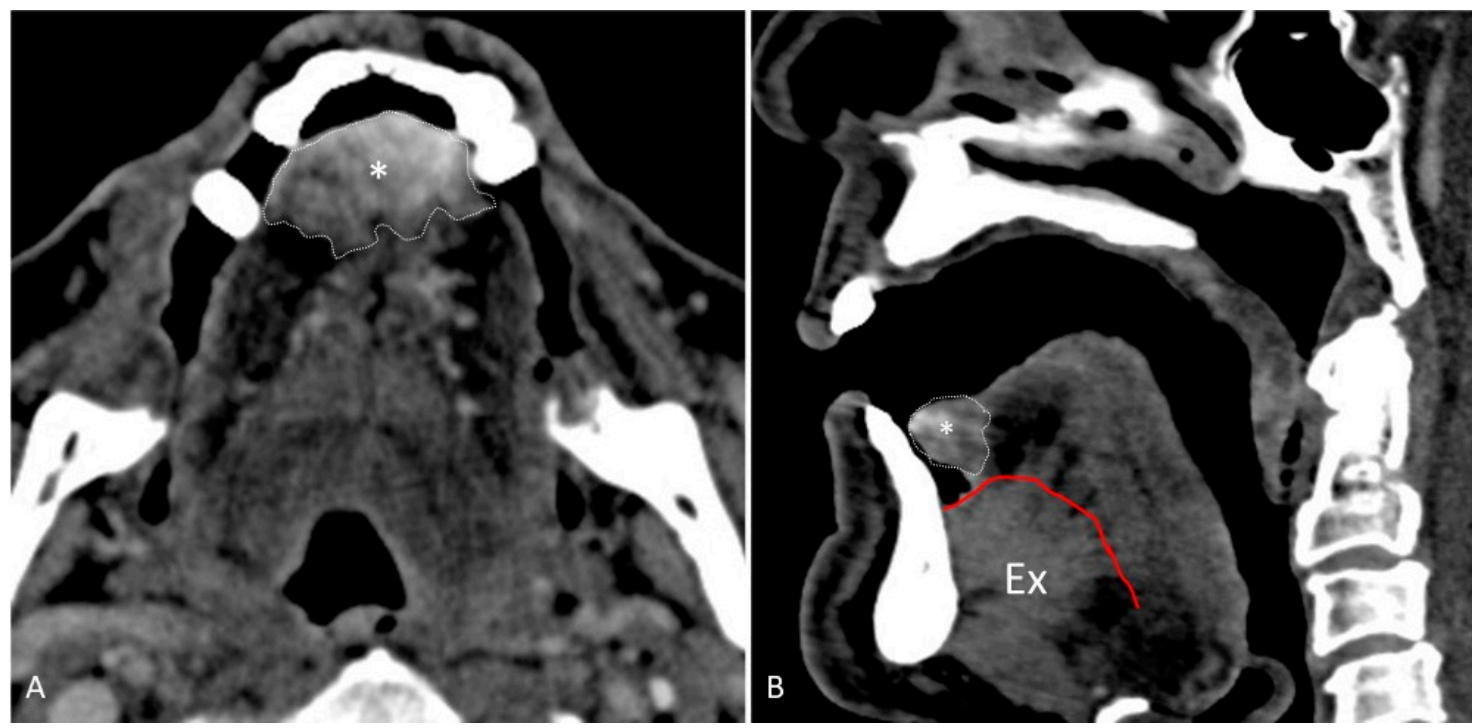

Figure 13. Open mouth MSCT technique. (A) Axial MSCT image of a squamous cell carcinoma of the lingual apex $(*$, outlined by the dotted line). This technique allows to separate the palatal mucosa from the muscular component of the tongue clarifying the exact origin, infiltration, and thickness of the lesion. (B) Sagittal MSCT image of the same patient. No infiltration of the extrinsic musculature of the tongue is observed (Ex, below the red line).

The open mouth technique also increases the visibility of structures obscured by dental metal artifacts, especially the soft palate but also the cheek, gingiva, oropharynx, and upper part of the mobile tongue, thus highlighting tumours or other diseases that are difficult to detect with the mouth closed (Figure 14).

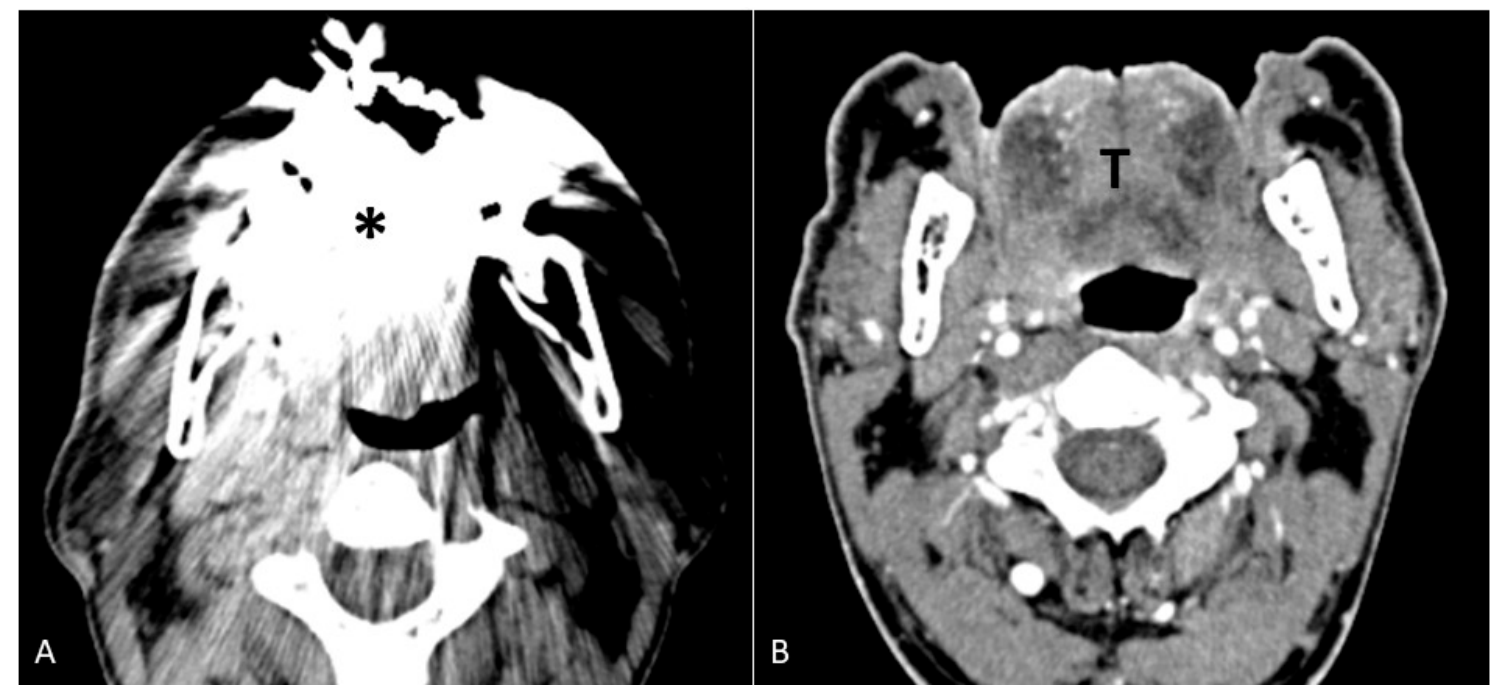

Figure 14. Open mouth MSCT technique. This technique can be also used to increase the visibility of the structures obscured by metal artifacts, especially the upper part of the mobile tongue. (A) Axial non-enhanced MSCT. The evaluation of the upper portion of the tongue in the standard scan is not possible due to large artifacts $\left(^{*}\right)$. (B) Axial contrast-enhanced open mouth MSCT of the same patient. The execution of the manoeuvre allows an easy assessment of the tongue $(\mathrm{T})$.

3. Mouth Opened with Tongue Extended. Patient must keep the mouth open and the tongue extended for the scan time while breathing through the nose (Figures 15 and 16). 


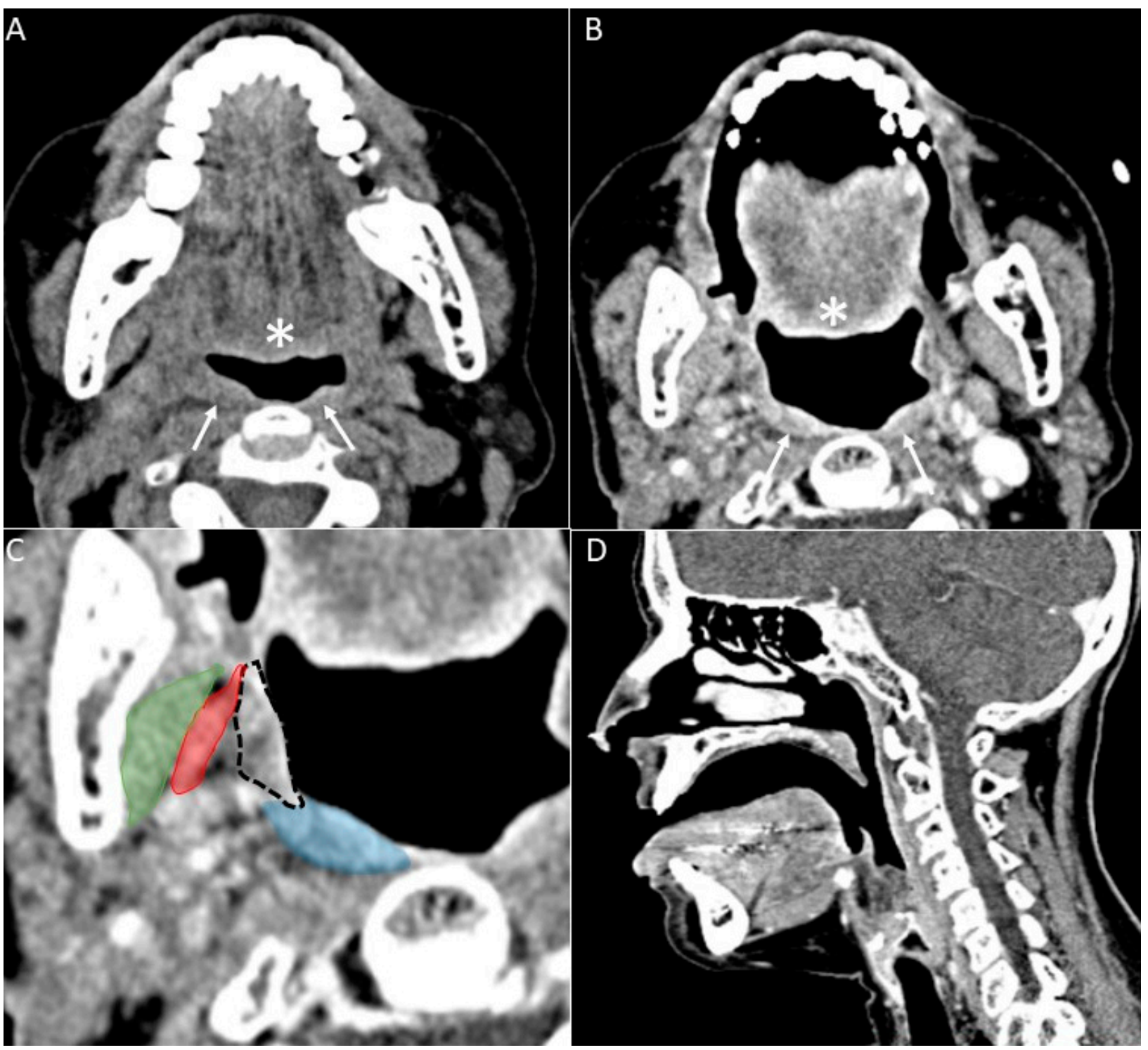

Figure 15. Open mouth with tongue extended MSCT technique. This manoeuvre allows to clearly separate the oral cavity from oropharyngeal structures. (A) Axial non-enhanced conventional MSCT acquisition at the level of the tongue base $\left(^{*}\right)$ and palatine tonsils (arrows). It is not possible to clearly distinguish the boundaries between the oral cavity and oropharynx making it difficult to assess a possible extension of a tonsillar neoplasm to the tongue base and adjacent muscles (or vice versa, a tongue neoplasm towards the tonsil). (B) Axial contrast-enhanced open mouth with tongue extended acquisition at the same level. Tongue and oropharynx with tonsils are "stretched", isolating these different compartments from each other. (C) Detailed image of (B) where it is possible to distinguish the palatine tonsil (blue), styloglossus muscle (red), medial pterygoid muscle (green), and glosso-tonsillar sulcus (dotted line). (D) Reconstructed sagittal image. 


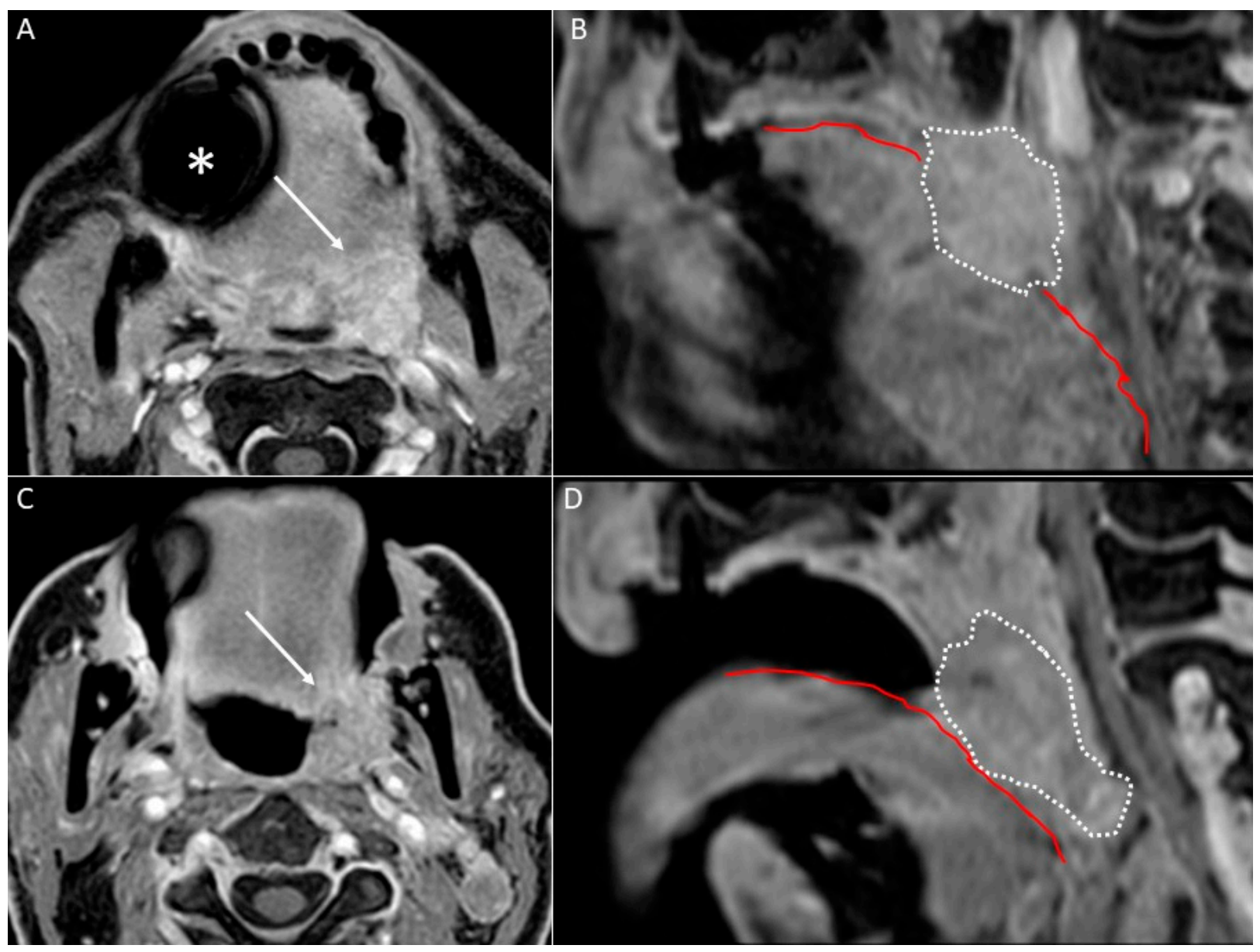

Figure 16. Open Mouth with Tongue extended MRI technique. (A) T1 contrast-enhanced axial image and (B) T1 contrast-enhanced sagittal image showing a left tonsillar neoplasm (arrow in (A), outlined by white dotted line in (B)) where it is not possible to distinguish between the infiltration of the tongue (outlined by the red line in (B)) and the surrounding muscles. (C) T1 contrast-enhanced axial open mouth with tongue extended and (D) T1 contrast-enhanced sagittal open mouth with tongue extended of the same patient where it is possible to appreciate how the neoplasm (arrow in (C), outlined by white dotted line in (D)) is well separated from the lingual surface (outlined by the red line in (D)) and neighbouring structures. The lingual protrusion causes "stretching" of the oropharyngeal structures and distends the glosso-tonsillar sulcus. Therefore, the tonsillar compartment is isolated. In case of tonsillar neoplasia, it is possible to confirm or deny the invasion of the tongue base, styloglossus, pterygoid muscles, and the lateral wall of the pharynx-and vice versa for a lingual neoplasm. In (A) a susceptibility artifact, given by the interface between the ferromagnetic material and the adjacent tissues causing magnetic distortions and signal loss, is clearly visible $\left({ }^{*}\right)$.

Proper instruction and testing of the manoeuvre are required before scanning. This technique reduces artifacts from metal material (for the same reasons of simple open mouth technique, the X-ray beam better penetrates the oral cavity without the interference of dental metal) (Figure 14) and enables a better visualisation of oral cavity/oropharynx tumours, thus allowing a more accurate staging [51]. Lingual protrusion causes "stretching" of the oropharyngeal structures and distends the glosso-tonsillar sulcus. Small lesions located on the lateral or ventral margin of the anterior tongue or located on the lingual apex are clearly highlighted by such manoeuvre [47].

4. Water distension of the oral vestibule. This technique is exclusively used on MRI examinations since MRI has a high contrast for liquids by using specific sequences, 
especially T2 sequences. Water distension of the oral vestibule is performed by asking patients to drink $20-40 \mathrm{~mL}$ of still water and keep it in the mouth for the time necessary to acquire the images ( $\mathrm{T} 2$ and pre- and post-contrast $\mathrm{T} 1$ sequences) [47]. This manoeuvre distends the oral vestibule and the presence of water provides excellent natural contrast between the lesion and the adjacent mucosal surfaces (Figure 17).

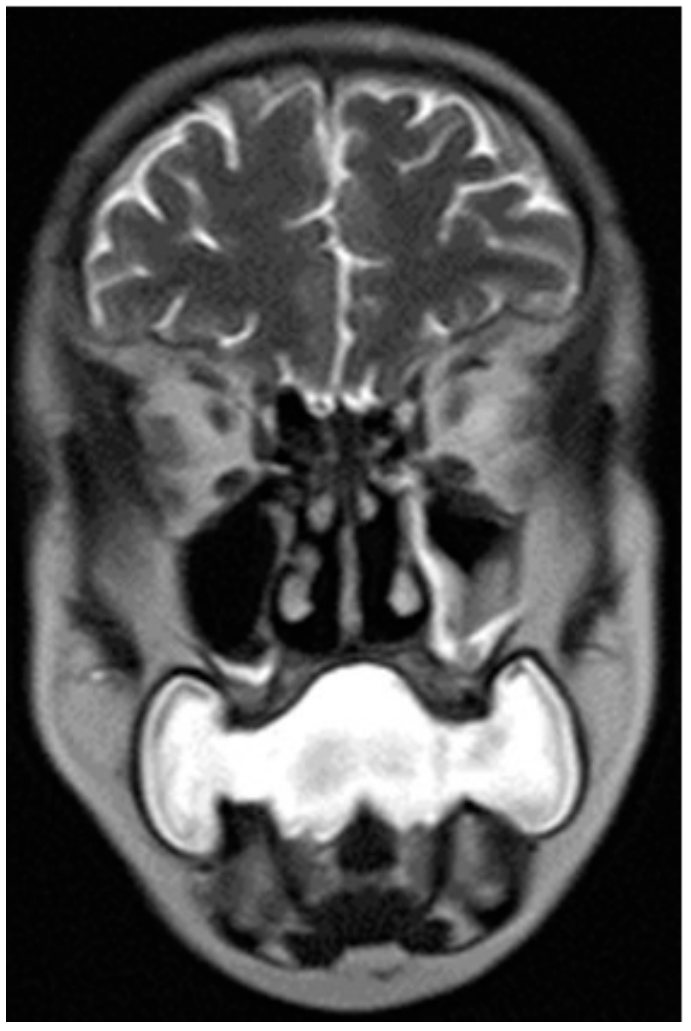

Figure 17. Water distension of oral vestibule. The presence of water in the oral vestibule enables a better delineation and distinction of the buccal and gingival mucosa, allowing a better analysis of possible abnormalities.

It is considered the best method for the assessment of tumours of the retromolar trigone and posterior buccal mucosa, as well as the identification of exophytic tongue lesions by distinguishing true exophytic from infiltrative alterations. Furthermore, the vestibule distension allows a better evaluation of patients both with submucosal fibrosisespecially chronic tobacco chewers-and postoperative fibrosis, where the inability to perform the puffed cheek technique and the more difficult clinical evaluation by ear-nosethroat specialists could hide lesions and relapses [47].

\section{Metal Artifacts and Stratagems for Their Reduction}

Both on MSCT and MRI images, the study of the oral cavity is frequently limited by the presence of artifacts caused by implants, pins, surgical plates, dental restorations, and orthodontic bands.

\subsection{MSCT}

Metal artifacts are given by two main phenomena on MSCT examinations that take the name of beam hardening and photon starvation (Figure 18) based on the different atomic numbers of dental materials [52]. 


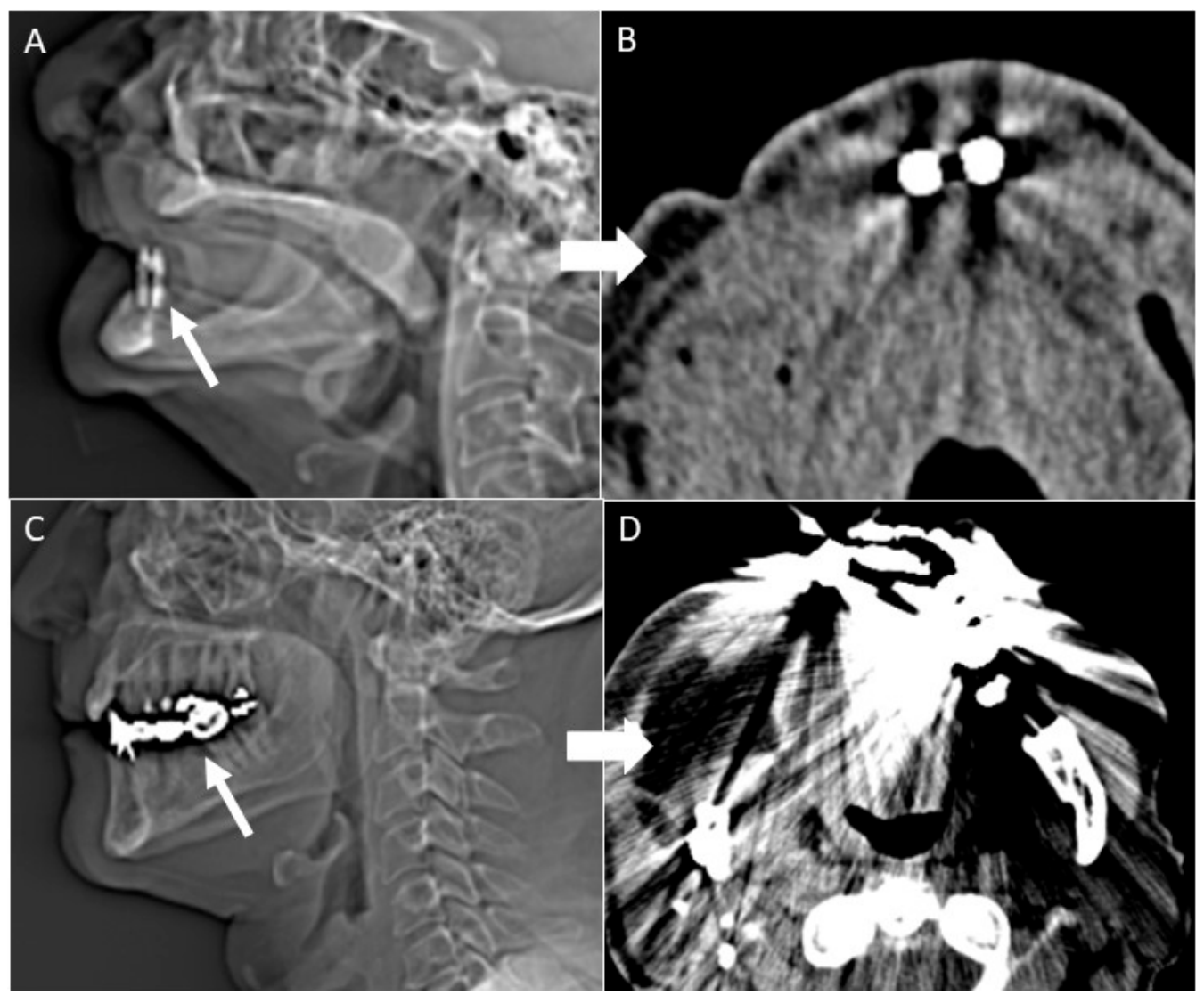

Figure 18. Dental metal artifacts on MSCT examinations. (A,B) Beam hardening artifacts occurring when the X-ray beam hits a metal with a low atomic number. (A) MSCT scout view shows two titanium implants located on the anterior lower jaw (arrow). (B) Axial image characterised by hypodense streaks gradually reducing from the area of interest towards the periphery. $(\mathbf{C}, \mathbf{D})$ Photon starvation artifacts occurring when the $\mathrm{X}$-ray beam hits a metal with a high thickness or high atomic number. (C) MSCT scout view in which many silver amalgam crowns and multiple dental restoration therapies are found. (D) Axial image shows the typical artifacts with alternated hypo/hyperdense streaks opening as a fan from the metallic area.

Beam hardening takes place when the X-ray beam hits metal materials with low atomic numbers (e.g., titanium $Z=22$ ). The metal absorbs radiation with lower energy, thus making the emerging beam "harder" since it is rich in high energy photons. Hypodense streaks gradually reducing from the area of interest towards the periphery is the typical aspect on MSCT images. On the contrary, when the X-ray beam hits metal materials with high thickness or atomic number (e.g., the amalgam: silver $Z=47$ and mercury $Z=80$ ), a very high attenuation takes place and a "photon starvation" occurs, that is the condition where there is not a sufficient number of photons reaching the detector. The appearance of this artifact on MSCT images is that of alternated hypo/hyperdense streaks opening as a fan from the metallic area [52]. By comparing MSCT with CBCT, dental metal artifacts are significantly lower on $\mathrm{CBCT}$ images for three main reasons including low tube current, limited dynamic range of the detector, and high number of reconstructions around the metal object enabled by the cone/pyramidal-shaped beam [52] (Figure 19). 

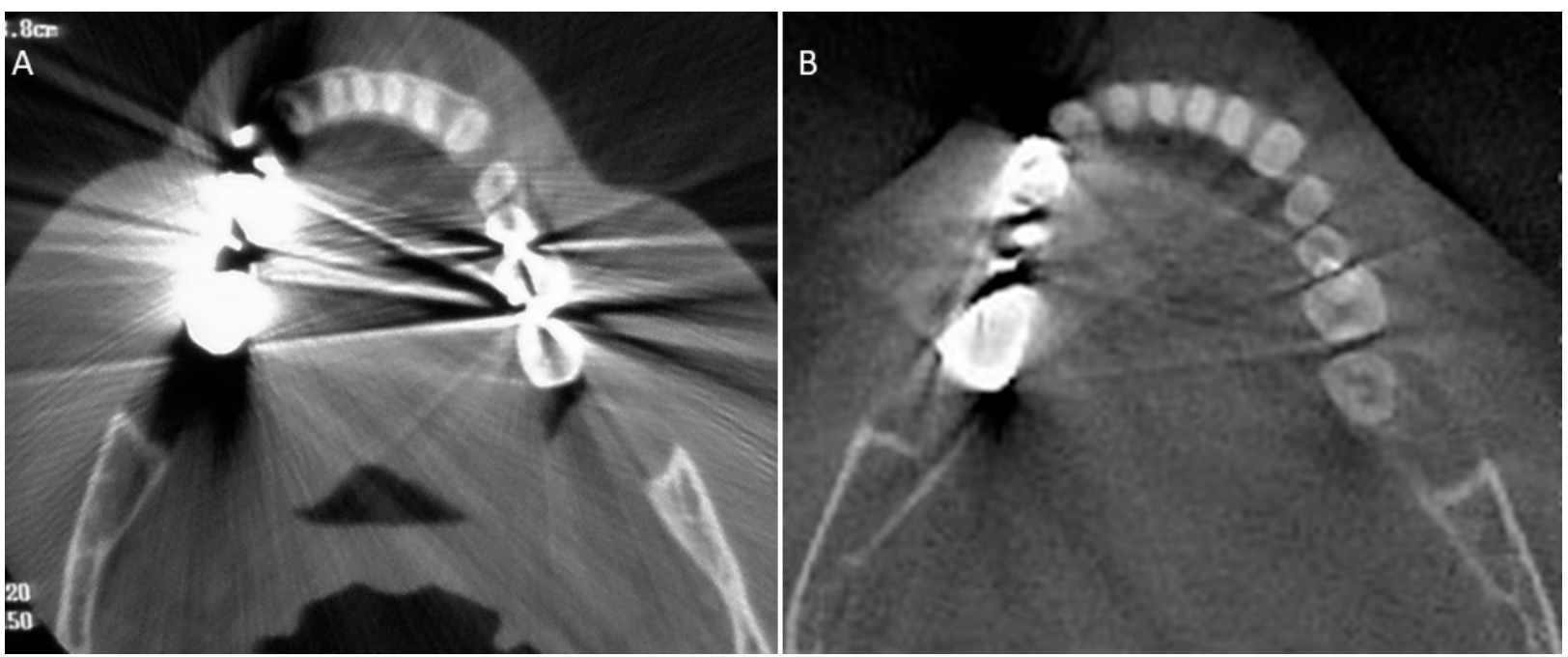

Figure 19. Dental metal artifacts. MSCT vs. CBCT. (A) Bone kernel-MSCT axial view of the lower jaw. (B) CBCT of the lower jaw carried out at the same level on the same patient. The artifacts from metal material are significantly less evident on CBCT images than MSCT ones.

Many "stratagems" have been employed over time to reduce metal artifacts on oral MSCT examinations including the examples described below with proven clinical efficacy.

- Gantry tilt scanning. Patients have to be positioned with tooth occlusal surfaces perpendicular to the table; the gantry tilt angle used is $\geq 20$ degrees. In the postprocessing phase the oblique images obtained are reconstructed to transverse images with information on the table position [53];

- $\quad$ Open mouth dynamic manoeuvre. See the above-mentioned paragraph and Figure 14);

- Metal artifact reduction algorithms. They replace the metal trace region with neighbouring data (also known as iterative reconstruction techniques) (Figure 20) [54].
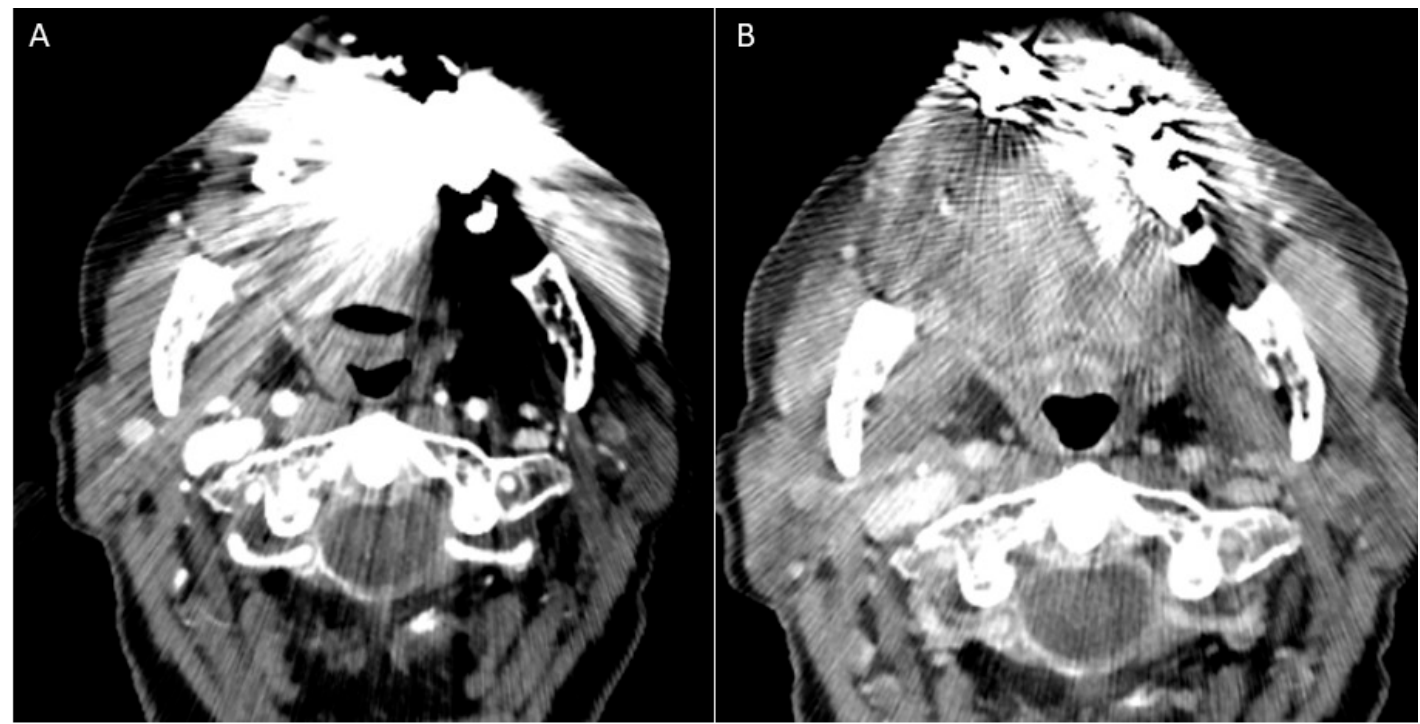

Figure 20. Metal Artifact Reduction Algorithms (MAR). (A) Axial contrast-enhanced standard MSCT with photon starvation artifacts. (B) Axial contrast-enhanced O-MAR (MAR for orthopaedic implants; Philips. the Netherlands) MSCT of the same patient. A better visualisation of the oral cavity structures is observed. This kind of algorithm uses iterative reconstruction techniques to replace data points identified as metal with interpolated values. 
These three different strategies can also be used in combination to improve the dental artifact reduction. For instance, Onodera et al. [55] used the gantry tilt combined with a metal artifact reduction algorithm and lateral position of the patient on the table.

\subsection{MRI}

Metal material in the oral cavity can generate two kinds of artifacts on MRI images. Susceptibility artifacts are given by the interface between dental materials and adjacent tissues that create a variation in the magnetic field strength, causing magnetic distortions and signal loss (Figure 16). Non-susceptibility artifacts are given by eddy currents induced by alternations of gradients and radiofrequency fields [56]. Susceptibility artifacts are responsible for almost all oral artifacts since magnetic field inhomogeneities are due to ferromagnetic ingredients contained in dental materials [57]. The high magnetic susceptibility within the magnetic field not only determines the signal loss but could also accumulate the signal intensity in the region of interest ("pile-up artifact"), resulting in an abnormally high signal intensity (Figure 21).

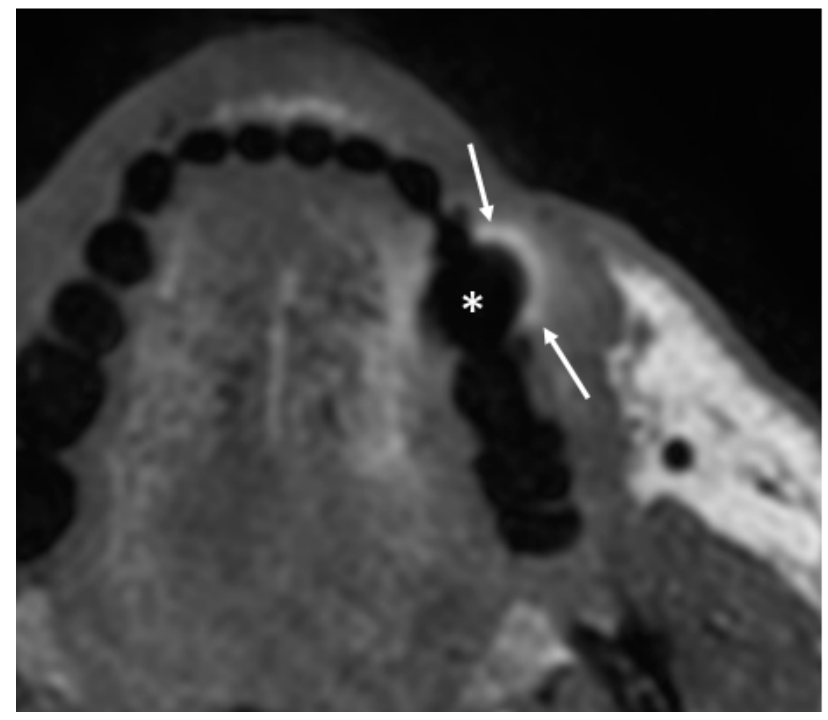

Figure 21. MRI "pile-up" artifact. The high magnetic susceptibility within the magnetic field could accumulate the signal intensity in the region of interest resulting in an abnormally high signal ("pileup artifact", indicated by white arrows). "Pile-up artifact" mainly occurs on the periphery of the area produced by magnetic distortions and signal loss given by the interface between dental metal materials and adjacent tissues $\left(^{*}\right)$.

The artifact severity will vary depending on the shape, position, orientation, number of objects in the image, and type/parameters of sequence used [57]. Different materials have different influences on the formation of the artifacts. Their magnitude is greater for titanium dental implants than zirconia ones [56]. Such artifacts can be reduced by some expedients:

- Spin-echo sequences with modified parameters (i.e., echo time, matrix, bandwidth, slice thickness, and echo train); high bandwidth per voxel, 3D spatial encoding, high-resolution matrix, and multi-echo spin-echo sequences or turbo/fast spin-echo sequences. Spin-echo sequences are less sensitive to susceptibility effects thanks to a $180^{\circ}$ radiofrequency pulse that refocuses the spins diminishing the phase shifts in the voxel and therefore the field inhomogeneity [58];

- Gradient echo sequence with a very short echo time. These sequences are metalsensitive and the signal loss is due to the intravoxel dephasing. Shortening the echo time and decreasing the voxel size can diminish the intravoxel dephasing and therefore the artifacts [58]; 
- Optimised metal artifact-free sequences with a specific intensity and size of susceptibility artifacts, including the multi-acquisition variable-resonance image combination (MAVRIC) and slice encoding for metal artifact correction (SEMAC) techniques. SEMAC uses a slice selection gradient for excitation and a view-angle tilting compensation gradient for readout. MAVRIC and SEMAC show significantly smaller artifact extent than fast spin-echo imaging [59].

Beyond artifacts, we should always remember that undesirable effects caused by the interaction of oral metal materials with the magnetic field also include the magnetically induced displacement and radiofrequency heating. The magnet can attract ferromagnetic objects, but the retention force of the dental cement $(50-150 \mathrm{~N})$ is strong enough to prevent the displacement of the prosthesis. However, position and fixing of the prosthesis must be inspected before and after every MRI examination because of the possibility of degeneracy cement phenomena [60]. The radiofrequency heating phenomenon causes a negligible rise in temperature, negligible even using a $3 \mathrm{~T}$ magnet $\left(<2{ }^{\circ} \mathrm{C}\right)$, that does not injure the prosthesis-neighbouring tissues and especially the richly vascularised periodontal ligament [54]. For further information on the use, safety, and diagnostic value of MRI in the presence of different metal materials and devices, please refer to the guidelines drawn up by Chokattu et al. [60].

\section{Conclusions}

The oral cavity is a complex anatomical area that can be affected by several different developmental, inflammatory, and tumoural diseases. The study of oral oncological pathology is mainly carried out via MSCT and MRI, that play a crucial role both in pre-surgical planning and in recognising any relapse after treatment. This paper summarised the imaging techniques used for the study of the oral cavity, with particular attention to promising results shown by DWI and DCE-PWI. Dynamic manoeuvres that help in the identification of "hidden" mucosal lesions and the tricks for metal artifact reduction were also described.

Funding: This research received no external funding.

Institutional Review Board Statement: Not applicable.

Informed Consent Statement: Informed consent was obtained from all subjects involved in the study.

Data Availability Statement: Not applicable.

Conflicts of Interest: The authors declare no conflict of interest.

\section{References}

1. Peres, M.A.; Macpherson, L.M.; Weyant, R.J.; Daly, B.; Venturelli, R.; Mathur, M.R.; Listl, S.; Celeste, R.K.; Guarnizo-Herreño, C.C.; Kearns, C.; et al. Oral diseases: A global public health challenge. Lancet 2019, 394, 249-260, Erratum in Lancet 2019, $394,1010$. [CrossRef]

2. Gondak, R.; Da Silva-Jorge, R.; Jorge, J.; Lopes, M.; Vargas, P.A. Oral pigmented lesions: Clinicopathologic features and review of the literature. Med. Oral Patol. Oral Cir. Bucal. 2012, 17, e919-e924. [CrossRef] [PubMed]

3. Montero, P.H.; Patel, S.G. Cancer of the Oral Cavity. Surg. Oncol. Clin. N. Am. 2015, 24, 491-508. [CrossRef] [PubMed]

4. Farah, C. Narrow Band Imaging-guided resection of oral cavity cancer decreases local recurrence and increases survival. Oral Dis. 2018, 24, 89-97. [CrossRef]

5. Ridgway, J.M.; Armstrong, W.B.; Guo, S.; Mahmood, U.; Su, J.; Jackson, R.P.; Shibuya, T.; Crumley, R.L.; Gu, M.; Chen, Z.; et al. In Vivo Optical Coherence Tomography of the Human Oral Cavity and Oropharynx. Arch. Otolaryngol.—Head Neck Surg. 2006, 132, 1074-1081. [CrossRef]

6. Mazziotti, S.; Ascenti, G.; Scribano, E.; Mileto, A.; Racchiusa, S.; Visalli, C.; Salamone, I.; Vinci, S.; Blandino, A. CT-MR integrated diagnostic imaging of the oral cavity: Neoplastic disease. La Radiol. Med. 2012, 118, 123-139. [CrossRef] [PubMed]

7. Law, C.P.; Chandra, R.; Hoang, J.K.; Phal, P.M. Imaging the oral cavity: Key concepts for the radiologist. Br. J. Radiol. 2011, 84, 944-957. [CrossRef] [PubMed]

8. Nardi, C.; Talamonti, C.; Pallotta, S.; Saletti, P.; Calistri, L.; Cordopatri, C.; Colagrande, S. Head and neck effective dose and quantitative assessment of image quality: A study to compare cone beam CT and multislice spiral CT. Dentomaxillofac. Radiol. 2017, 46, 20170030. [CrossRef] [PubMed] 
9. Ng, S.-H.; Yen, T.-C.; Liao, C.-T.; Chang, J.T.-C.; Chan, S.-C.; Ko, S.-F.; Wang, H.-M.; Wong, H.-F. ${ }^{18}$ F-FDG PET and CT/MRI in oral cavity squamous cell carcinoma: A prospective study of 124 patients with histologic correlation. J. Nucl. Med. 2005, 46, 1136-1143.

10. King, K.G.; Kositwattanarerk, A.; Genden, E.; Kao, J.; Som, P.M.; Kostakoglu, L. Cancers of the Oral Cavity and Oropharynx: FDG PET with Contrast-enhanced CT in the Posttreatment Setting. RadioGraphics 2011, 31, 355-373. [CrossRef]

11. Linz, C.; Brands, R.C.; Herterich, T.; Hartmann, S.; Müller-Richter, U.; Kübler, A.C.; Haug, L.; Kertels, O.; Bley, T.A.; Dierks, A.; et al. Accuracy of 18-F Fluorodeoxyglucose Positron Emission Tomographic/Computed Tomographic Imaging in Primary Staging of Squamous Cell Carcinoma of the Oral Cavity. JAMA Netw. Open 2021, 4, e217083. [CrossRef] [PubMed]

12. Roele, E.D.; Timmer, V.C.M.L.; Vaassen, L.A.A.; van Kroonenburgh, A.M.J.L.; Postma, A.A. Dual-Energy CT in Head and Neck Imaging. Curr. Radiol. Rep. 2017, 5, 19. [CrossRef] [PubMed]

13. Subramaniam, N.; Poptani, H.; Schache, A.; Bhat, V.; Iyer, S.; Sunil, H.; Chandrasekhar, N.H.; Pillai, V.; Chaturvedi, P.; Krishna, S.H.; et al. Imaging advances in oral cavity cancer and perspectives from a population in need: Consensus from the UK-India oral cancer imaging group. J. Head Neck Physicians Surg. 2021, 9, 4. [CrossRef]

14. Drage, N.; Qureshi, S.; Lingam, R. Imaging patients with cancer of the oral cavity. Br. Dent. J. 2018, 225, 827-832. [CrossRef]

15. Varma, R.; Tibrewala, S.; Roplekar, S. Computed Tomography Evaluation of Oral Cavity and Oropharyngeal Cancers. Int. J. Otorhinolaryngol. Clin. 2013, 5, 51-62. [CrossRef]

16. Filauro, M.; Missale, F.; Marchi, F.; Iandelli, A.; Carobbio, A.L.C.; Mazzola, F.; Parrinello, G.; Barabino, E.; Cittadini, G.; Farina, D.; et al. Intraoral ultrasonography in the assessment of DOI in oral cavity squamous cell carcinoma: A comparison with magnetic resonance and histopathology. Eur. Arch. Oto-Rhino-Laryngol. 2020, 278, 2943-2952. [CrossRef]

17. Lechuga, L.; Weidlich, G.A. Cone Beam CT vs. Fan Beam CT: A Comparison of Image Quality and Dose Delivered Between Two Differing CT Imaging Modalities. Cureus 2016, 8, e778. [CrossRef]

18. Nardi, C.; Salerno, S.; Molteni, R.; Occhipinti, M.; Grazzini, G.; Norberti, N.; Cordopatri, C.; Colagrande, S. Radiation dose in non-dental cone beam CT applications: A systematic review. La Radiol. Med. 2018, 123, 765-777. [CrossRef]

19. Nardi, C.; Vignoli, C.; Pietragalla, M.; Tonelli, P.; Calistri, L.; Franchi, L.; Preda, L.; Colagrande, S. Imaging of mandibular fractures: A pictorial review. Insights Imaging 2020, 11, 30. [CrossRef]

20. Miracle, A.; Mukherji, S. Conebeam CT of the Head and Neck, Part 2: Clinical Applications. Am. J. Neuroradiol. 2009, 30, 1285-1292. [CrossRef]

21. Hosono, M.; Takenaka, M.; Monzen, H.; Tamura, M.; Kudo, M.; Nishimura, Y. Cumulative radiation doses from recurrent PET/CT examinations. Br. J. Radiol. 2021, 94, 20210388. [CrossRef] [PubMed]

22. Atli, E.; Uyanik, S.A.; Oguslu, U.; Cenkeri, H.C.; Yilmaz, B.; Gumus, B. Radiation doses from head, neck, chest and abdominal CT examinations: An institutional dose report. Diagn. Interv. Radiol. 2021, 27, 147-151. [CrossRef] [PubMed]

23. Al-Okshi, A.; Lindh, C.; Salé, H.; Gunnarsson, M.; Rohlin, M. Effective dose of cone beam CT (CBCT) of the facial skeleton: A systematic review. Br. J. Radiol. 2015, 88, 20140658. [CrossRef] [PubMed]

24. Arya, S.; Rane, P.; Deshmukh, A. Oral cavity squamous cell carcinoma: Role of pretreatment imaging and its influence on management. Clin. Radiol. 2014, 69, 916-930. [CrossRef] [PubMed]

25. Patel, S.; Bhatt, A.A. Imaging of the sublingual and submandibular spaces. Insights Imaging 2018, 9, 391-401. [CrossRef]

26. Mazziotti, S.; Blandino, A.; Gaeta, M.; Bottari, A.; Sofia, C.; D’Angelo, T.; Ascenti, G. Postprocessing in Maxillofacial Multidetector Computed Tomography. Can. Assoc. Radiol. J. 2015, 66, 212-222. [CrossRef]

27. Notani, K.-I.; Yamazaki, Y.; Kitada, H.; Sakakibara, N.; Fukuda, H.; Omori, K.; Nakamura, M. Management of mandibular osteoradionecrosis corresponding to the severity of osteoradionecrosis and the method of radiotherapy. Head Neck 2002, 25, 181-186. [CrossRef]

28. Henrot, P.; Blum, A.; Toussaint, B.; Troufléau, P.; Stines, J.; Roland, J. Dynamic Maneuvers in Local Staging of Head and Neck Malignancies with Current Imaging Techniques: Principles and Clinical Applications. RadioGraphics 2003, 23, 1201-1213. [CrossRef]

29. Nardi, C.; Tomei, M.; Pietragalla, M.; Calistri, L.; Landini, N.; Bonomo, P.; Mannelli, G.; Mungai, F.; Bonasera, L.; Colagrande, S. Texture analysis in the characterization of parotid salivary gland lesions: A study on MR diffusion weighted imaging. Eur. J. Radiol. 2021, 136, 109529. [CrossRef]

30. Ogura, I.; Sasaki, Y.; Kameta, A.; Sue, M.; Oda, T. Diffusion-Weighted Imaging in the Oral and Maxillofacial Region: Usefulness of Apparent Diffusion Coefficient Maps and Maximum Intensity Projection for Characterization of Normal Structures and Lesions. Pol. J. Radiol. 2017, 82, 571-577. [CrossRef]

31. Oda, T.; Sue, M.; Sasaki, Y.; Ogura, I. Diffusion-weighted magnetic resonance imaging in oral and maxillofacial lesions: Preliminary study on diagnostic ability of apparent diffusion coefficient maps. Oral Radiol. 2017, 34, 224-228. [CrossRef] [PubMed]

32. Razek, A.A.K.A.; Megahed, A.S.; Denewer, A.; Motamed, A.; Tawfik, A.; Nada, N. Role of diffusion-weighted magnetic resonance imaging in differentiation between the viable and necrotic parts of head and neck tumors. Acta Radiol. 2008, 49, 364-370. [CrossRef] [PubMed]

33. Kito, S.; Morimoto, Y.; Tanaka, T.; Tominaga, K.; Habu, M.; Kurokawa, H.; Yamashita, Y.; Matsumoto, S.; Shinohara, Y.; Okabe, S.; et al. Utility of diffusion-weighted images using fast asymmetric spin-echo sequences for detection of abscess formation in the head and neck region. Oral Surg. Oral Med. Oral Pathol. Oral Radiol. Endodontol. 2006, 101, 231-238. [CrossRef] [PubMed]

34. Wang, J.; Takashima, S.; Takayama, F.; Kawakami, S.; Saito, A.; Matsushita, T.; Momose, M.; Ishiyama, T. Head and Neck Lesions: Characterization with Diffusion-weighted Echo-planar MR Imaging. Radiology 2001, 220, 621-630. [CrossRef] 
35. Wendl, C.M.; Müller, S.; Eiglsperger, J.; Fellner, C.; Jung, E.M.; Meier, J.K. Diffusion-weighted imaging in oral squamous cell carcinoma using 3 Tesla MRI: Is there a chance for preoperative discrimination between benign and malignant lymph nodes in daily clinical routine? Acta Radiol. 2015, 57, 939-946. [CrossRef]

36. Zhou, Y.; Yu, T.; Rui, X.; Jin, T.; Huang, Z.; Huang, Z. Effectiveness of diffusion-weighted imaging in predicting cervical lymph node metastasis in head and neck malignancies. Oral Surg. Oral Med. Oral Pathol. Oral Radiol. 2020, 131, 122-129.e2. [CrossRef]

37. Freihat, O.; Pinter, T.; Kedves, A.; Sipos, D.; Cselik, Z.; Repa, I.; Kovács, Á. Diffusion-Weighted Imaging (DWI) derived from PET/MRI for lymph node assessment in patients with Head and Neck Squamous Cell Carcinoma (HNSCC). Cancer Imaging 2020, 20, 56. [CrossRef]

38. Tawfik, A.M.; Razek, A.A.; Kerl, J.M.; Nour-Eldin, N.-E.A.; Bauer, R.; Vogl, T.J. Comparison of dual-energy CT-derived iodine content and iodine overlay of normal, inflammatory and metastatic squamous cell carcinoma cervical lymph nodes. Eur. Radiol. 2013, 24, 574-580. [CrossRef]

39. Yabuuchi, H.; Fukuya, T.; Tajima, T.; Hachitanda, Y.; Tomita, K.; Koga, M. Salivary Gland Tumors: Diagnostic Value of Gadoliniumenhanced Dynamic MR Imaging with Histopathologic Correlation. Radiology 2003, 226, 345-354. [CrossRef]

40. Gaddikeri, S.; Tailor, T.; Anzai, Y. Dynamic Contrast-Enhanced MR Imaging in Head and Neck Cancer: Techniques and Clinical Applications. Am. J. Neuroradiol. 2015, 37, 588-595. [CrossRef]

41. Choi, Y.J.; Lee, J.H.; Sung, Y.S.; Yoon, R.G.; Park, J.E.; Nam, S.Y.; Baek, J.H. Value of Dynamic Contrast-Enhanced MRI to Detect Local Tumor Recurrence in Primary Head and Neck Cancer Patients. Medicine 2016, 95, e3698. [CrossRef] [PubMed]

42. Guo, N.; Zeng, W.; Deng, H.; Hu, H.; Cheng, Z.; Yang, Z.; Jiang, S.; Duan, X.; Shen, J. Quantitative dynamic contrast-enhanced MR imaging can be used to predict the pathologic stages of oral tongue squamous cell carcinoma. BMC Med. Imaging 2020, 20, 117. [CrossRef] [PubMed]

43. Maraghelli, D.; Pietragalla, M.; Cordopatri, C.; Nardi, C.; Peired, A.J.; Maggiore, G.; Colagrande, S. Magnetic Resonance Imaging of salivary gland tumours: Key findings for imaging characterisation. Eur. J. Radiol. 2021, 139, 109716. [CrossRef] [PubMed]

44. Matsuzaki, H.; Yanagi, Y.; Hara, M.; Katase, N.; Asaumi, J.-I.; Hisatomi, M.; Unetsubo, T.; Konouchi, H.; Takenobu, T.; Nagatsuka, H. Minor salivary gland tumors in the oral cavity: Diagnostic value of dynamic contrast-enhanced MRI. Eur. J. Radiol. 2012, 81, 2684-2691. [CrossRef] [PubMed]

45. Yan, S.; Wang, Z.; Li, L.; Guo, Y.; Ji, X.; Ni, H.; Shen, W.; Xia, S. Characterization of cervical lymph nodes using DCE-MRI: Differentiation between metastases from SCC of head and neck and benign lymph nodes. Clin. Hemorheol. Microcirc. 2016, 64, 213-222. [CrossRef]

46. King, A.D.; Thoeny, H.C. Functional MRI for the prediction of treatment response in head and neck squamous cell carcinoma: Potential and limitations. Cancer Imaging 2016, 16, 23. [CrossRef]

47. Shah, D. Dynamic manoeuvres on MRI in oral cancers-A pictorial essay. Indian J. Radiol. Imaging 2020, 30, 334-339. [CrossRef]

48. Weissman, J.L.; Carrau, R.L. "Puffed-cheek" CT improves evaluation of the oral cavity. Am. J. Neuroradiol. 2001, 22, 741-7444.

49. Bhat, V.; Kuppuswamy, M.; Kumar, D.S.; Karthik, G. Pneumoparotid in "puffed cheek" computed tomography: Incidence and relation to oropharyngeal conditions. Br. J. Oral Maxillofac. Surg. 2015, 53, 239-243. [CrossRef]

50. Bhat, V.; Hadne, N.; Tobias, R. Air Leak into the Soft Tissues during the Puffed Cheek CT Evaluation of Oral Cavity: Diagnosis and Implication of a Rare Phenomenon. J. Maxillofac. Oral Surg. 2016, 16, 374-376. [CrossRef]

51. Bron, G.; Scemama, U.; Villes, V.; Fakhry, N.; Salas, S.; Chagnaud, C.; Bendahan, D.; Varoquaux, A. A new CT dynamic maneuver "Mouth Opened with Tongue Extended" can improve the clinical TNM staging of oral cavity and oropharynx squamous cell carcinomas. Oral Oncol. 2019, 94, 41-46. [CrossRef] [PubMed]

52. Nardi, C.; Borri, C.; Regini, F.; Calistri, L.; Castellani, A.; Lorini, C.; Colagrande, S. Metal and motion artifacts by cone beam computed tomography (CBCT) in dental and maxillofacial study. La Radiol. Med. 2015, 120, 618-626. [CrossRef] [PubMed]

53. Nakae, Y.; Sakamoto, K.; Minamoto, T.; Kamakura, T.; Ogata, Y.; Matsumoto, M.; Johkou, T. Clinical evaluation of a newly developed method for avoiding artifacts caused by dental fillings on X-ray CT. Radiol. Phys. Technol. 2007, 1, 115-122. [CrossRef] [PubMed]

54. Wei, Y.; Jia, F.; Hou, P.; Zha, K.; Pu, S.; Gao, J. Clinical application of multi-material artifact reduction (MMAR) technique in Revolution CT to reduce metallic dental artifacts. Insights Imaging 2020, 11, 32. [CrossRef]

55. Onodera, M.; Aratani, K.; Shonai, T.; Ogura, K.; Kamo, K.-I.; Ogi, K.; Kondo, A.; Hatakenaka, M. Lateral Position with Gantry Tilt Further Improves Computed Tomography Image Quality Reconstructed Using Single-Energy Metal Artifact Reduction Algorithm in the Oral Cavity. J. Comput. Assist. Tomogr. 2020, 44, 553-558. [CrossRef]

56. Bohner, L.; Meier, N.; Gremse, F.; Tortamano, P.; Kleinheinz, J.; Hanisch, M. Magnetic resonance imaging artifacts produced by dental implants with different geometries. Dentomaxillofac. Radiol. 2020, 49, 20200121. [CrossRef]

57. Klinke, T.; Daboul, A.; Maron, J.; Gredes, T.; Puls, R.; Al Jaghsi, A.; Biffar, R. Artifacts In Magnetic Resonance Imaging and Computed Tomography Caused By Dental Materials. PLoS ONE 2012, 7, e31766. [CrossRef]

58. Lee, M.-Y.; Song, K.-H.; Lee, J.-W.; Choe, B.-Y.; Suh, T.S. Metal artifacts with dental implants: Evaluation using a dedicated CT/MR oral phantom with registration of the CT and MR images. Sci. Rep. 2019, 9, 754. [CrossRef]

59. Gunzinger, J.M.; Delso, G.; Boss, A.; Porto, M.; Davison, H.; Von Schulthess, G.K.; Huellner, M.; Stolzmann, P.; Veit-Haibach, P.; Burger, I.A. Metal artifact reduction in patients with dental implants using multispectral three-dimensional data acquisition for hybrid PET/MRI. EJNMMI Phys. 2014, 1, 102. [CrossRef]

60. Chockattu, S.J.; Suryakant, D.B.; Thakur, S. Unwanted effects due to interactions between dental materials and magnetic resonance imaging: A review of the literature. Restor. Dent. Endod. 2018, 43, e39. [CrossRef] 